\title{
Metal Hydrides in Engineering Systems, Processes, and Devices: A Review of Non-storage Applications
}

\author{
by \\ MD Mainul Hossain Bhuiya, Anupam Kumar, and Kwang J. Kim* \\ Department of the Mechanical Engineering \\ University of Nevada, Las Vegas \\ *kwang.kim@unlv.edu
}

\begin{abstract}
Metal hydrides have garnered much interest in scientific and engineering communities since their discovery in 1866 because of the wide range of applications they offer [1, 2]. A comprehensive review of selected applications involving metal hydrides in engineering systems, processes and devices has been presented in this paper. The applications of metal hydrides can be broadly classified into seven distinct categories, which are: 1) thermal systems, 2) energy systems, 3) actuation and sensing, 4) processing, 5) semiconductors, 6) biomimetic and biomedical systems, and 7) nuclear applications in addition to hydrogen storage. There have been several brilliant reviews published on hydrogen storage in metal hydrides $[118$, . The focus of this review is on non-storage metal hydride applications. The fundamentals and working principles of engineering systems, processes, and devices based on metal hydrides have been concisely provided. Besides hydrogen storage, metal hydrides have been proposed and demonstrated for applications in hydrogen compressors, refrigerators, and actuators. Optical and electrical properties of hydrides can be exploited in the design of sensors and energy efficient windows. The hydriding and dehydriding processes are effective in preparing implants for osseointegration in addition to being economic. Certain hydride materials are more effective neutron moderators compared to the conventional ones in nuclear power plants. All such applications involving metal hydrides are revised and briefly discussed along with their working principles in this article.
\end{abstract}

Keywords: Metal Hydrides, Hydrogen, Heat Storage, Sensors, Batteries 


\section{Introduction}

Metal hydrides were first discovered in 1866 by Thomas Graham [1]. The first metal hydride discovered was palladium hydride $\left(\mathrm{PdH}_{\mathrm{x}}\right)[1,2]$. Numerous other metal hydrides have been discovered after palladium hydride. They have been established as excellent media for on-board or stationary hydrogen storage. The sole reason behind the superiority of metal hydrides as storage media over competing/existing technology is their ability to store large amounts of hydrogen at densities greater than cryogenically stored liquid hydrogen. Moreover, the discharge pressure can be close to atmospheric pressure at moderate temperatures for some hydrides, which makes them more suitable for portable systems. Besides, the properties of hydrides such as storage capacity, operating pressure and temperature can be altered by alloying as well as other mechanical means. Thus, metal hydrides are vigorously researched for on board vehicular hydrogen storage systems that are capable of storing enough hydrogen to cover approximately 300 miles of conventional driving range with a single refill.

Apart from hydrogen storage, metal hydrides had been integrated in various engineering applications. These systems take advantage of high storage capacity of metal hydrides and temperature/pressure swing dependent sorption method. The concept of temperature swing causing a low pressure absorption and high pressure desorption is utilized in designing thermally driven hydrogen compressors. Based on the fact that absorption and desorption processes are exothermic and endothermic, respectively, metal hydride storage systems can be engineered to supply heated or cooled air for application in air conditioning, refrigeration, and heat pumps. Those properties can also be exploited in designing thermochemical heat storage system. Apart from thermal systems, metal hydrides are also well known for their application in energy systems such as metal hydride batteries and fuel cells. $A_{5}$ type metal hydrides are used in the production of more than a billion batteries every year. Proton exchange membrane (PEM) fuel cells have the potential to replace the internal combustion engine in future. The chemical energy of hydrogen stored in metal hydrides is converted to DC power in these cells, which can be used to drive the DC motor of the vehicle. The ultra-high storage capability of a metal hydride can be translated to high force to weight ratio from the desorbed hydrogen, which makes it a suitable candidate for actuation of robotic arms and biomimetic muscles.

There are some metallic hydrides, which exhibit optical and electrical property change on top lattice expansion while they undergo hydrogen absorption. Changes in such properties make them potential 
candidates for designing gas sensors capable of integrating micro systems. The change in optical properties in the presence of hydrogen enables application of metal hydrides in smart windows. Certain metallic coatings have been found to switch from transparent to opaque in the presence and absence of hydrogen, respectively. Hydrogen purification and isotope separation processes have also been demonstrated using metal hydride as a storage material. From a mix of gases, only hydrogen gets absorbed in the storage material and the remaining gases can be purged by previously purified hydrogen gas. Certain metals like palladium show affinity towards different isotopes of hydrogen in different temperature ranges. Such properties are taken advantage of, in the design of isotope separation processes for industrial applications.

Finally, comparatively newer field of applications have been proposed and demonstrated by integrating hydrides materials in semiconductor electronics, osseointegration, and fast nuclear reactors. Certain hydrides show $p$-type and $n$-type conductivity as revealed from the analysis of their band structure. Such hydrides open up the potential of a new era of 'hydride electronics'. Some biocompatible metals such as titanium are used in living systems for implantation. Very often the material needs to be transformed into powder before it is compressed into desired shape. This process is expensive and can be replaced with an economic hydrogenation/dehydrogenation process, which eventually breaks up crude particles or agglomerates into finer powder after repeated cycles of sorption. The ability of hydrogen atoms in a hydride to moderate fast neutrons in nuclear reactors encouraged researchers to use hafnium hydrides as neutron moderators. Also, certain actinide hydride fuels have been suggested as transmutation targets of long lived nuclear wastes.

Metal hydride has been an interesting topic among scientists and engineers with ongoing research emphasis. As time progresses and hydrogen evolves as a future fuel to suffice the world's energy needs, new generation of metallic alloys could be developed to minimize the shortcomings of the contemporaries. Along the way, hydrides have found interesting engineering applications besides hydrogen storage. Many more applications of hydride may be underway as new characteristics of such materials are discovered. This article summarizes the fundamentals behind the applications of metal hydrides in thermal, energy, actuator and sensors, industrial, biomedical, and nuclear systems as proposed and demonstrated in research and publications. 


\section{Metal Hydride Basics}

Although, there are at least fifty metallic elements in the periodic table that can store hydrogen, only a handful of them are suitable for storing it at moderate temperatures and pressures. The process is nearly reversible and can be expressed by the following equation.

$$
M+\frac{x}{2} H_{2} \leftrightarrow M H_{x} \pm \Delta H
$$

Where $M$ and $H$ represent metal and hydrogen atoms, respectively. Note that $x$ is the nonstoichiometric coefficient and $\Delta H$ is the reaction enthalpy. The sorption process is exothermic when hydrogen is absorbed in and endothermic when hydrogen is desorbed from the alloy.

Hydrogen is stored in the interstitial sites of metals with densities greater than liquid hydrogen as shown in Figure 1. Even though mass percentage seems to be very low, for portable applications such as vehicular hydrogen storage, hydrides are very attractive alternatives because of ultra-high density. The limiting condition for applicability of metal hydrides is generally related to the applicable temperature and pressure. $A B_{5}$ type hydrides such $\mathrm{LaNi}_{5}$, however, show reversible sorption at desirable ranges of operating temperature and pressures. It is the extremely high density with moderate operating conditions that makes metal hydride a suitable candidate for portable hydrogen storage applications.

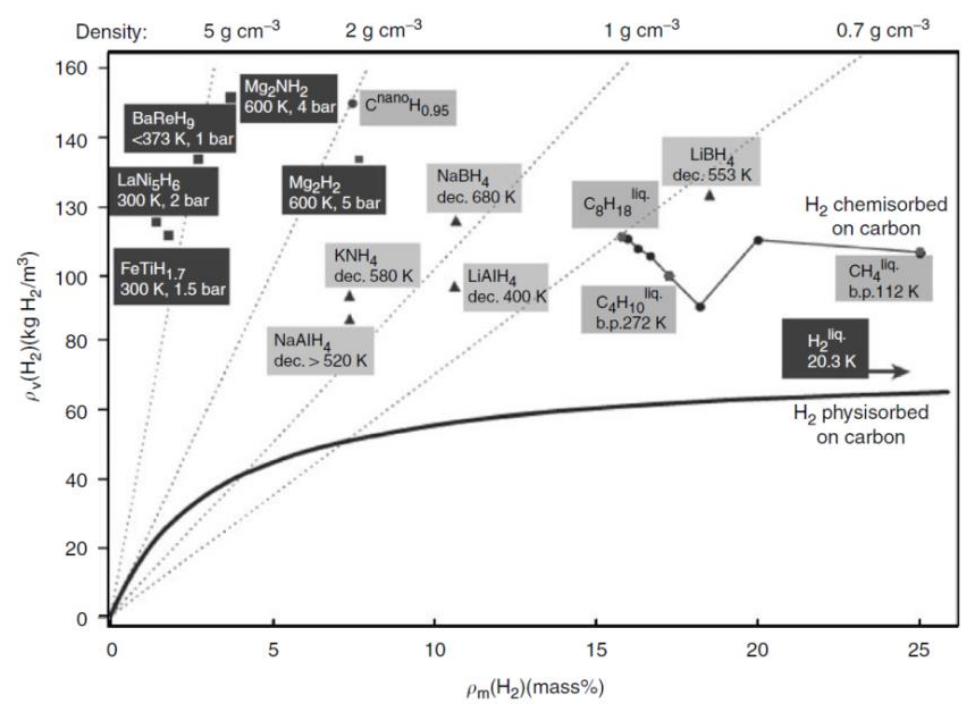

Figure 1: Comparison of metal hydrides with other storage systems, reprinted with permission from Schlapbach and Zuttel [4]) 
The most important feature of a metal hydride storage system is its plateau pressure, illustrated in Figure 2(a). This is the pressure at which metal hydrides reversibly absorb/desorb large quantities of hydrogen. For applications such as batteries, this plateau pressure is desired to be close to the ambient pressure, which allows designing the container with light weight material. There is a difference between equivalent pressures for absorption and desorption in the pressure-composition isotherms. This hysteresis can be reduced by mechanical means such as milling during the manufacturing process. The pressure plateaus for a certain compound generally increases (moves up in the chart) as temperature increases as shown in Figure 2(b). The operating characteristics of metal hydrides (e.g. $\mathrm{LaNi}_{5}$ ) can further be tuned to suit specific applications by the inclusion of limited amount of additional elements (e.g. tin) to the alloy lattice. This brings down the plateau pressure and increases cycle life by reducing the stacking faults occurring in the alloys. With the increasing temperature plateau pressures in natural log scale can be plotted against inverse of corresponding temperature, which would generate a linear plot shown in Figure 2(c). This plot is called the Van't Hoff plot, which is probably the single most important piece of information required for selection of appropriate types of metal hydrides for specific applications.

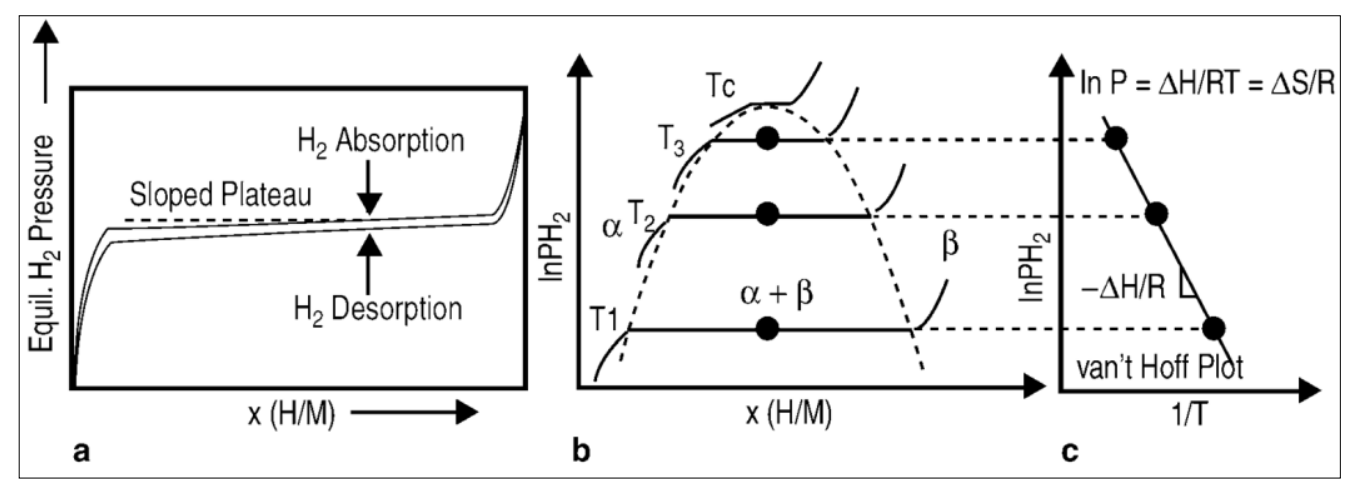

Figure 2: (a) Sorption isotherm showing hysteresis (b) typical phase diagram for a metal hydride showing the transformation from $\alpha$-phase to $\beta$-phase; (c) the Van't Hoff plot derived from the isotherms for various temperatures, reprinted with permission from Chandra, Reilly, and Chellappa [5]

The equilibrium behavior of metal hydrides in the plateau region can be described by Van't Hoff plots, according to the relation,

$$
\ln P_{H_{2}}=\frac{\Delta H}{R T}-\frac{\Delta S}{R}
$$


Here, $R$ is the molar gas constant ( $8.314 \mathrm{~kJ} / \mathrm{kgmole}-\mathrm{K}) ; T$ is the absolute temperature; $\Delta H$ is the enthalpy of absorption in $\mathrm{kJ} / \mathrm{kg}$-mole of $\mathrm{H}_{2}$; and $\Delta S$ is the standard entropy of formation in $\mathrm{kJ} / \mathrm{kg}-\mathrm{mole}$ of $\mathrm{H}_{2}-\mathrm{K}$. The enthalpy of the hydriding reaction, $\Delta H$, can be determined by calculating the slope of Equation (2). It is a measure of the metal-hydrogen bond strength and is instrumental for heat management required for engineering devices based on metal hydrides [3]. The Van't Hoff plot and the pressure-compositiontemperature (PCT) data available for metal hydrides are the basis for thermo-mechanical design. Van't Hoff plot for an array of metal hydrides, as shown in Figure 3, allows researchers to identify a design specific material [116]. The selection of the storage material is governed by the applicable operating temperature and pressure ranges for a desired application. If a system requires operating temperature range from room temperature to about $100^{\circ} \mathrm{C}$, for example, then the material falling in that window can be narrowed down by the upper and lower limit of the temperature range. The choice can be narrowed down further by identifying the limiting pressure range. For such temperature range and pressure within one atmosphere, the choice narrows down to $\mathrm{LaNi}_{5}, \mathrm{FeTi}$ and $\mathrm{NaAl}$ alloys. Finally the cost of the material and availability may dictate the selection of appropriate material. Hence, Van't Hoff plot plays a vital role in the design of metal hydride integrated devices. Other important properties which govern the choice of materials for engineering systems are reaction kinetics and cyclic stability of hydrides.

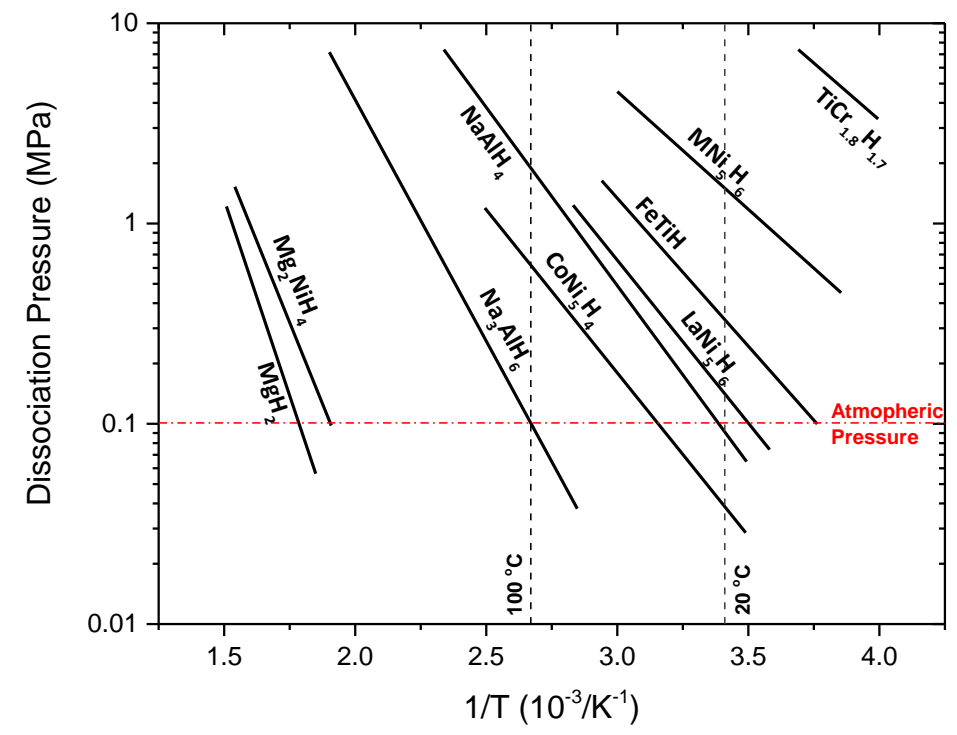

Figure 3: Van't Hoff's plot for different metal hydrides, adapted from Schuth, Bogdanovic, and Felderhoff [6] 


\section{Applications}

Metal hydrides have found numerous applications based on the equilibrium plateau pressure at a given temperature. Some metal hydrides have been commercialized while others are still in research and development phase. Nevertheless, the engineering applications of metal hydrides in practical systems can be broadly classified into:

3.1 Thermal Systems: hydrogen compressor, refrigeration, heat storage, thermal engine, etc.

3.2 Energy Systems: battery, fuel cells, etc.

3.3 Actuation and Sensing: actuators, gas sensors, smart windows, etc.

3.4 Processing: $\mathrm{H}_{2}$ purification, isotope separation, catalysis, etc.

3.5 Semiconductors: semiconducting hydrides for 'hydride electronics'

3.6 Biomimetic and Biomedical Systems: pre-process for implant material preparation

3.7 Nuclear: neutron moderator, transmutation

In the following sections, fundamentals and working principles of each of these systems have been consciously reviewed.

\subsection{Thermal Systems}

\subsubsection{Compressor}

Thermally driven metal hydride hydrogen compressor $[7-21,119]$ is one of the prominent systems involving hydrogen storage materials. Taking advantage of the reversibility of absorption and desorption of hydrogen by temperature swing, the compressor operates in a closed loop thermodynamic cycle. The operating cycle, illustrated in Figure 4, begins with the initiation of the formation of hydride phase as marked by $D$ in the pressure concentration isotherm. Along the isotherm, the metallic storage material absorbs hydrogen till it reaches saturation point $A$ at a lower pressure $P_{L}$ in thermodynamic equilibrium. At this point the absorption phase is complete and hydrogen is absorbed inside the metal hydride at a moderately lower temperature and pressure. As the temperature of the system is subsequently increased to a higher level than the absorption temperature, desorption process is initiated following a higher pressure concentration isotherm at elevated pressure. For an elevated temperature $T_{H}$ the initiation of desorption process is marked by $B$ at an equilibrium pressure higher than the absorption pressure. As this higher temperature is maintained, the system keeps desorbing the gas along the isotherm at a higher equilibrium pressure. The process continues until point $C$ is reached where almost 
all the hydrogen is extracted from the storage material at an elevated equilibrium pressure $\mathrm{P}_{\mathrm{H}}$. Hence, thermally driven hydrogen compression systems form a closed loop where hydrogen is absorbed into the system at lower temperature $\left(T_{L}\right)$ and pressure $\left(P_{L}\right)$ and subsequently desorbed at an elevated temperature $\left(T_{H}\right)$ and pressure $\left(P_{H}\right)$. Such compressors do not require moving parts and thus they are noiseless and environmentally benign. Reported compression ratios for such system are very high ranging from 3 to $10[10,11,15]$. Such systems can also be assembled in series for multiple stages of compression, thereby generating a compression ratio of over 12 [8].

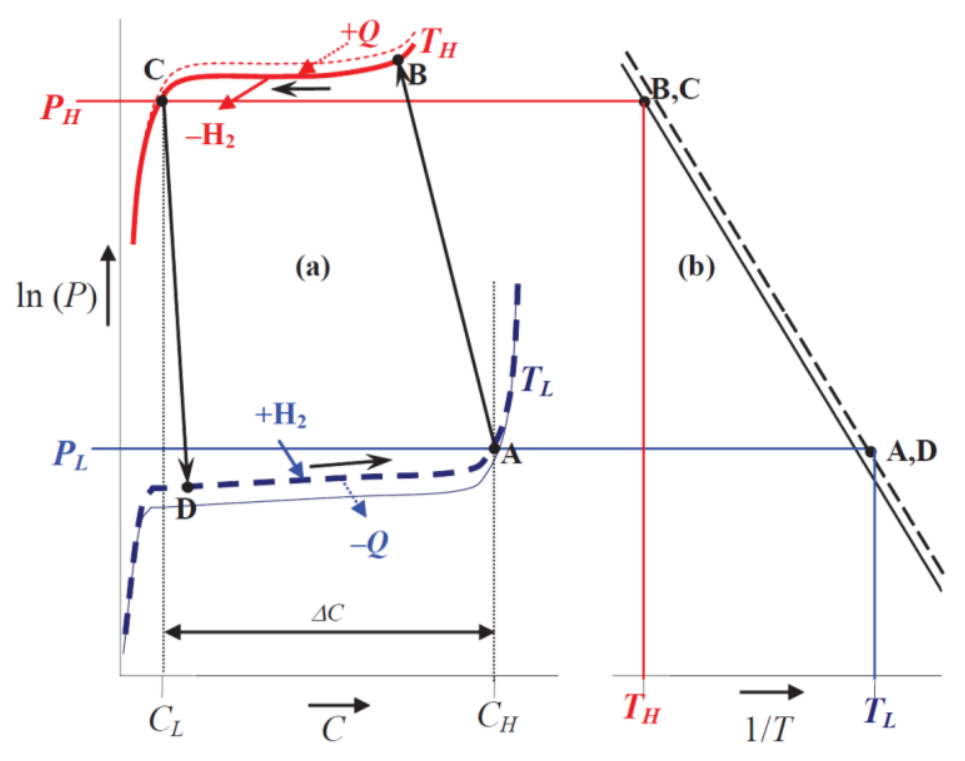

Figure 4: Thermally driven metal hydride compressor operating cycle. (a) Absorption isotherm in solid and desorption isotherm in dashed line shown for lower and higher operating temperatures. (b) Van't Hoff plots for illustrating temperature dependencies of the plateau pressure for the operating range, reprinted with permission from Lototskyy et al [19]

\subsubsection{Refrigerator, Air conditioner and Heat Pump}

Metal hydrides store and desorb hydrogen through a reversible chemical reaction that incorporates evolution and absorption of heat, respectively. The exothermic reaction during absorption of hydrogen can be utilized in the heat pump whereas the absorption of heat during the endothermic reaction associated with desorption can be utilized for cooling. Metal hydride refrigerator [22-30] and heat pump [29-42] take advantage of the heat absorption and desorption phenomena during desorption and absorption of hydrogen into the storage reactor beds, respectively. For heating or cooling application, metal hydride integrated devices usually have two identical reaction beds filled with same type of storage material having different affinity to hydrogen gas. Use of similar type of material simplifies the cycle coordination for heating or cooling. Initially, one of the beds is completely charged with hydrogen 
while the other is devoid of hydrogen. A typical metal hydride heat pump (MHHP) consists of a pair of hydrides: a high-pressure, low-temperature (HP-LT) hydride (B) and a low-pressure, high-temperature (LP-HT) hydride (A). The operation of a simple MHHP is illustrated in Figure 5 using a van't Hoff plot. The operation of a MHHP consists of two half-cycles. During the first half-cycle hydride A desorbs hydrogen at a high pressure, $P_{H}$ by taking up heat $Q_{H}$ at an elevated temperature, $T_{H}$. The heat of absorption, $Q_{m 1}$ is released to the sink at temperature, $T_{m}$. Then, the temperature of hydride $A$ is brought down from $T_{H}$ to $T_{m}$ and that of hydride $B$ from $T_{m}$ to $T_{L}$, sensibly. This marks the completion of the first half-cycle. During the second half-cycle, hydride $B$ desorbs hydrogen at a low pressure, $P_{L}$ by taking up cold $Q_{L}$ at a low temperature, $T_{L}$. This is absorbed by hydride $A$ releasing heat $Q_{m 2}$ at a temperature of $T_{m}$. This is followed by heating hydrides $A$ and $B$ from $T_{m}$ to $T_{H}$ and $T_{L}$ to $T_{m}$, respectively. This marks the completion of the second half-cycle. The heat pump is thus ready for the subsequent half-cycles of operation.

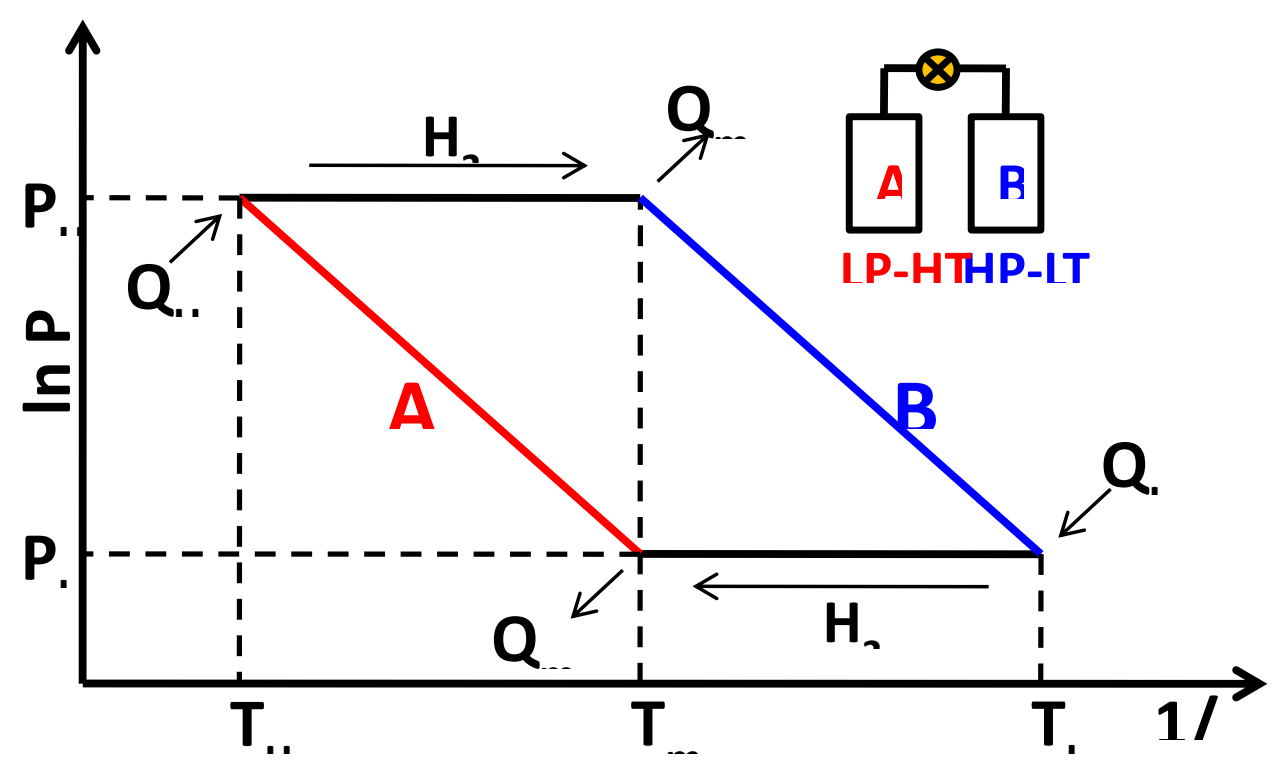

Figure 5: Thermodynamic cycle of a metal hydride heat pump (MHHP), reprinted with permission from Altinisik and Veziroglu [43]

Such systems utilizing metal hydrides are primarily used for cooling applications and are known as Metal Hydride Cooling Systems (MHCS). For quasi-continuous cooling, a pair of high-pressure, lowtemperature (HP-LT) hydrides and a pair of low-pressure, high-temperature (LP-HT) hydrides are used. Such metal hydride cooling system (MHCS) operates between two pressure levels and is known as a 
single-stage single-effect system [23]. Similarly, a double-stage double-effect system uses three pairs of metal hydrides in order to obtain a quasi-continuous cold output. Such system operates between three pressure levels. Double-stage double-effect systems have significantly better COPs compared to singlestage single-effect systems, with the trade-off of increasing the cooling system inventory [23, 38].

Gopal and Murthy [44] carried out experimental investigations on a metal hydride cooling system (MHCS) working with $\mathrm{ZrMnFe} / \mathrm{MmNi}_{4.5} \mathrm{Al}_{0.5}$ pair where $\mathrm{MmNi}_{4.5} \mathrm{Al}_{0.5}(800 \mathrm{~g})$ served as the high-pressure, low-temperature (HP-LT) alloy and ZrMnFe (700 g) as the low-pressure, high-temperature (LP-HT) alloy. They studied the hydrogen transfer processes in which hydrogen was transferred from LP-HT to HP-LT during the first half cycle and from HP-LT to LP-HT during the second half cycle. The half-cycle times were maintained at 3-12 minutes. Other operating conditions were heat source temperature $\left(T_{H}=110\right.$ $\left.130^{\circ} \mathrm{C}\right)$, heat sink temperature $\left(T_{m}=23-30^{\circ} \mathrm{C}\right)$, and refrigeration temperature $\left(T_{L}=5-15^{\circ} \mathrm{C}\right)$. They obtained a specific cooling power (SCP) that varied from 30 to $45 \mathrm{~W} / \mathrm{Kg}$ and a COP varying from 0.2 to 0.35 depending upon the operating conditions.

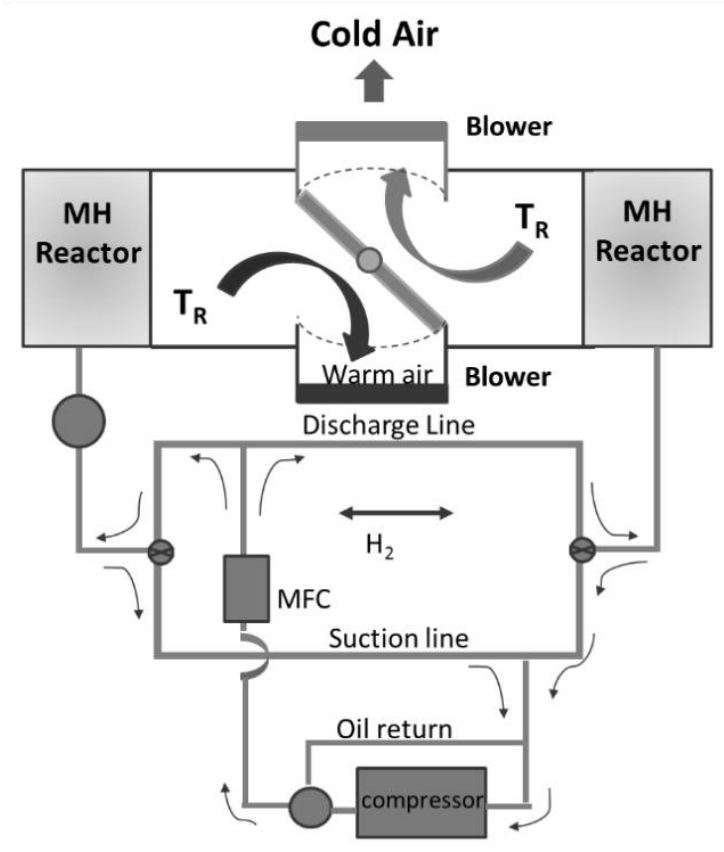

Figure 6: Compressor driven metal hydride heat pump, adapted from Park, Han, and Jang [39]

A vivid illustration of a compressor driven metal hydride heat pump (CD-MHHP) was provided and prototyped by Jeong et al [39]. The schematic diagram of the concept is shown in Figure 6. Their system was able to attain a COP of 1.8 with a half cycle time of 3 minute with the minimum cooling temperature 
of $6^{\circ} \mathrm{C}$. To maintain the flow of hydrogen in such a system, a compressor driven by a variable speed motor incorporated in the design as shown in the figure. An insulated air damper regulates the flow of air over the reactors alternatively. When hydrogen is extracted from the charged reactor, air from the room is blown over that reactor which takes up the heat of reaction from the room air. As a result, the outlet of the system discharges cold air inside the room. The discharged hydrogen from this reactor is passed on to the second reactor which absorbs hydrogen and cooled by the flow of ambient air. Once the first reactor is depleted and the second one is charged with hydrogen, the orientation of the air damper changes to allow room air to blow over the second reactor while desorption process continues in that reactor. Hence, continuous supply of cold air is maintained inside the room by alternating desorption cycle in two reactors and regulating the flow of room air using the air damper.

Libowitz et al. [33] described a novel heat driven metal hydride heat pump (MHHP) which utilizes the concept of a crossed van't Hoff cycle. Here, the heat required by the regeneration hydride is supplied by the regeneration alloy. The major advantage of such a heat pump is that the theoretical values of cooling coefficient of performances (COPs) are considerably higher than those of conventional hydride heat pumps. The van't Hoff plot of such a system is shown in Figure 7. A one dimensional heat pipe is used transfer the heat of absorption of the refrigeration hydride to the regeneration hydride. The major disadvantage the crossed van't Hoff concept is the requirement of higher temperatures and pressures for regeneration than the conventional systems which limits the use of some hydrides. Libowitz et al. employed the following refrigeration/regeneration hydride pairs in their experiments: $\mathrm{LaNi}_{5} / \mathrm{V}_{0.855} \mathrm{Ti}_{0.095} \mathrm{Fe}_{0.05}, \quad \mathrm{Fe}_{0.9} \mathrm{Mn}_{0.1} \mathrm{Ti} / \mathrm{V}_{0.846} \mathrm{Ti}_{0.104} \mathrm{Fe}_{0.05}, \quad \mathrm{MmNi}_{3.98} \mathrm{Fe}_{1.04} / \mathrm{V}_{0.846} \mathrm{Ti}_{0.104} \mathrm{Fe}_{0.05}, \quad$ and $\mathrm{MmNi}_{3.98} \mathrm{Fe}_{0.85} / \mathrm{VCr}_{0.05}$. Out of these metal hydride pairs, the $\mathrm{LaNi}_{5} / \mathrm{V}_{0.855} \mathrm{Ti}_{0.095} \mathrm{Fe}_{0.05}$ pair yielded the highest theoretical COP of 2.5. For the same hydride pair, the theoretical COP is 0.72 which is considerably lower than the heat pump in the crossed van't Hoff configuration. However, due to heat losses the experimental COP values for the crossed van't Hoff and the conventional heat pump are 0.85 and 0.64 . Other metal hydride based advanced cooling and heating systems have been proposed by researches, for example, metal hydride thermal wave concept was developed by Dehouche et al. [39], cascading systems analyzed by Klein and Groll [21], and multi-stage systems described by Willers and Groll [45]. These and other systems have been described in an excellent review by Muthukumar and Groll [23]. 


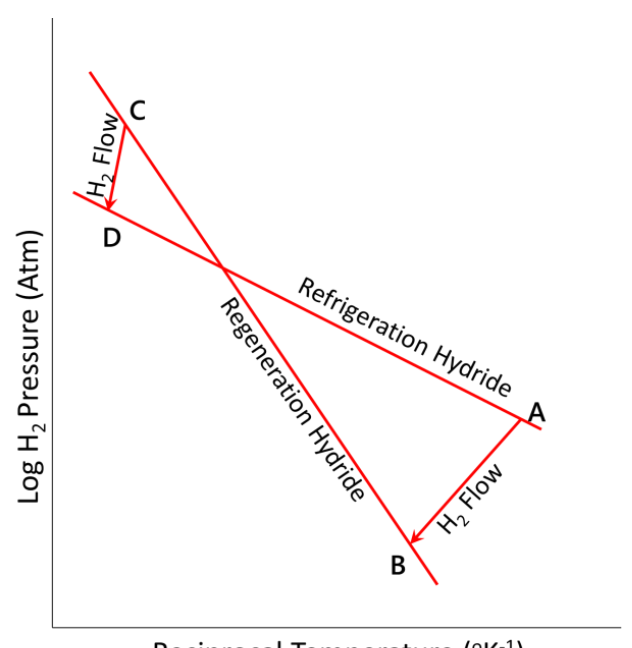

Reciprocal Temperature $\left({ }^{\circ} \mathrm{K}^{-1}\right)$

Figure 7: Metal hydride heat pump based on crossed van't Hoff plot, reprinted with permission from Libowitz, G. G., Feldman Jr., K. T., and Stein [33]

\subsubsection{Heat Storage}

Thermally driven hydrogen transport phenomenon that occurs during the absorption and desorption process in metal hydrides enables these materials to be used as reversible chemical heat storage [48-56] systems. Several studies have demonstrated high temperature thermochemical heat storage using magnesium [49, 51] based light weight thermal storage alloys. The concept has been applied to prototype a process steam generator [49], which was primarily designed for storage of high grade industrial waste heat. The principle behind the thermochemical heat storage using metal hydrides consists of storing heat in the storage material from the heat source by exciting the endothermic chemical reaction and recovering heat by reversing the reaction [51]. The energy density attainable in this process is very high and duration of storage can be as long as desired. For heat storage purpose $\mathrm{Mg}$ based light weight and high temperature storage materials are under serious investigation by researchers because of high heat storage capacity, low material cost and excellent cycle life [56].

\subsubsection{Thermal Engine}

From the perspective of chemical to mechanical energy conversion metal hydrides can be integrated into applications such as heat engine. A heat engine using $\mathrm{LaNi}_{5}$ as a conversion medium and a piston and cylinder for mechanical power output has been prototyped and investigated [55, 58]. Figure 8 shows the basic arrangement of the chemical engine proposed by Nomura et al [58]. In this engine, high pressure gas is supplied to the piston cylinder in the forward stroke and hydrogen is absorbed in the low 
pressure container during the return stroke. Electromagnetic valves are used to synchronize pressurized gas supply to and from the storage material and the piston. The heating and cooling temperature is $80^{\circ} \mathrm{C}$ and $20^{\circ} \mathrm{C}$ respectively for the reactor to desorb and absorb hydrogen. Although the theoretical conversion efficiency had been anticipated to be about 15\%, a 7.7\% [58] conversion efficiency has been attained experimentally (Figure 8).

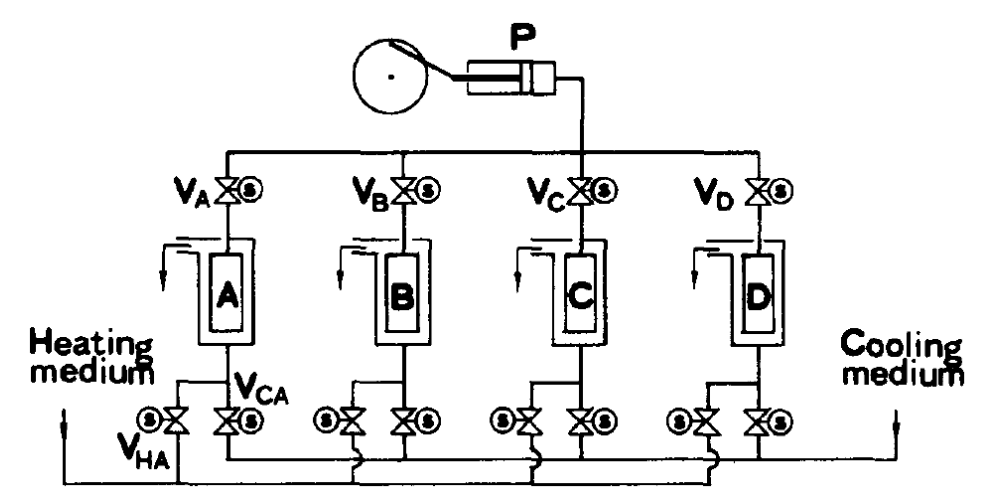

Figure 8: Metal hydride integrated "chemical engine", reprinted with permission from Nomura, Ishido, and Ono [58]

\subsubsection{Sorption Cryoccolers}

Metal hydrides have successfully been used in sorption cryocoolers for cooling of telescopes in space applications. A telescope aboard a spaceflight consists of a high frequency instrument (HFI) and a low frequency instrument (LFI), both of which need to be cooled to cryogenic temperatures in order to reduce the signal to noise ratio. A sorption cryocooler is a vibration free cooling system with no moving parts. In fact, the only moving parts the valves that open and close very slowly and exert only a negligible force, thereby producing no vibrations on the spacecraft [59] A simplified schematic diagram of a sorption cooler has been shown in Figure 9. A sorption cooler works with the combination of a thermal compressor element (CE) and a Joule-Thompson (J-T) expander. A metal hydride acts as the compressor element. Because of its combination of the desired characteristics of long cycle life, high volumetric capacity, and low plateau pressure, $\mathrm{LaNi}_{4.78} \mathrm{Sn}_{0.22}$, is the metal hydride of choice for the sorbent bed. It can absorb large amounts hydrogen gas at relatively low pressures ( 0.5 bar) at around the room-temperature. When heated in a limited volume, it releases the stored hydrogen and produces high-pressure hydrogen gas. This is illustrated in Figure 9 as the heat up (Pressurization) cycle (B-C). This is followed by de-sorption (C-D), expansion (D-A), and ab-sorption (A-B) cycles. Hydrogen gas is passed through a Joule-Thompson (J-T) expander and liquefaction of hydrogen is achieved. Cooling is accomplished by "boiling" this liquid hydrogen from the heat from sensors. Figure 9 is a simplified 
schematic of a cryocooler operation. The actual system consists of several sorbent beds in sequence capable of being independently heated or cooled. Continuous refrigeration is achieved when one of the sorbent beds is desorbing while the others are eitherheating, cooling, or absorbing hydrogen gas. Sorption coolers have been used in the Brilliant Eyes Ten-Kelvin Sorption Cryocooler Experiment (BETSCE) to produce a temperature of $10 \mathrm{~K}[60]$ and in the European Space Agency (ESA) Plank flight mission to produce a temperature of less than $20 \mathrm{~K}$ [59], respectively. A gas gap heat switch (consisting of another metal hydride) alternatively isolates and connects the sorbent bed from the radiator (heat sink). The heat switch prevents the loss of excessive amounts of heat during the heating cycle and allows the removal of heat during the cooling cycle.
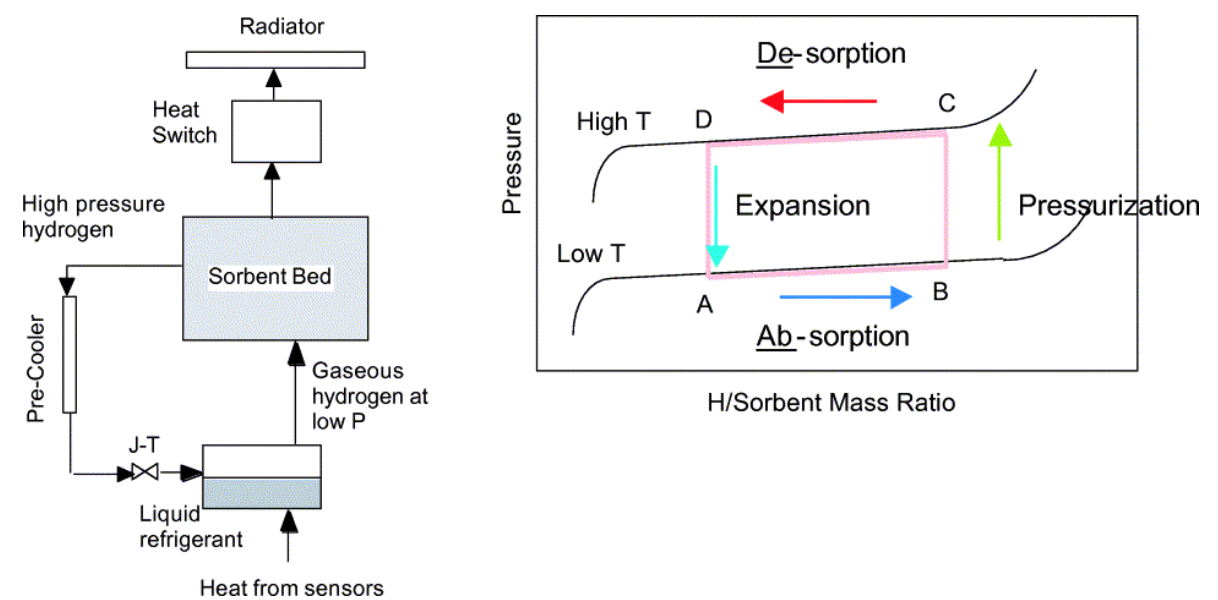

Figure 9: Schematic of a sorption cryocooler, reprinted with permission from Bhandari et al. [59]

\subsubsection{Gas Gap Heat Switch}

A Gas Gap Heat Switch (GGHS) is a device which provides variable thermal conductance between two objects by changing the pressure of gas in a closed volume between the surfaces of the two objects. Since hydrogen has the highest thermal conductance of all gases, it is used as the gas ideally. The material used as the gas gap heat switch is a metal hydride. GGHSs have been used in high temperature batteries [61, 62] and sorption cryocoolers as described in the previous section. Typically, ZrNi [63], ZrVFe [61], and Uranium [1] based alloys are used as GGHSs. A schematic of a GGHS for cryocoolers is shown in Figure 10. A gap of $0.75 \mathrm{~mm}$ is provided between the sorbent bed (e.g. $\mathrm{LaNi}_{4.78} \mathrm{Sn}_{0.22}$ ) and the gas gap actuator (e.g. ZrNi). Thermal conductance is accomplished when heat is transferred from the sorbent bed to the heat switch through hydrogen molecules. At low pressures, there are very few hydrogen molecules and they mostly strike the surfaces of the materials (molecular regime). As such, 
thermal conductance between the surfaces is more efficient in the molecular regime, but the number of gas molecules is so low that only a very small amount of heat is transferred in between the surfaces. This represents the pressure $\mathrm{P}_{\mathrm{OFF}}$ in Figure 11 below which the heat switch is in "OFF" state [64]. On the other hand, at high pressures, hydrogen molecules mostly collide with each other (viscous regime). But because of the availability of a large number of gas molecules for heat transport, heat is transferred efficiently in between the surfaces. This is shown as $\mathrm{P}_{\mathrm{ON}}$ in Figure 11, above which the heat switch is in "ON" state.

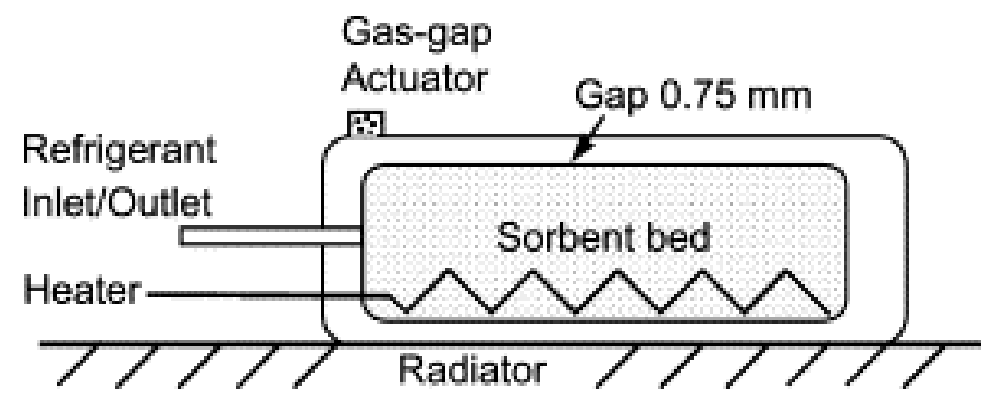

Figure 10: Schematic of a Gas Gap Heat Switch used in sorption cryocoolers, reprinted with permission from Prina et al. [63]

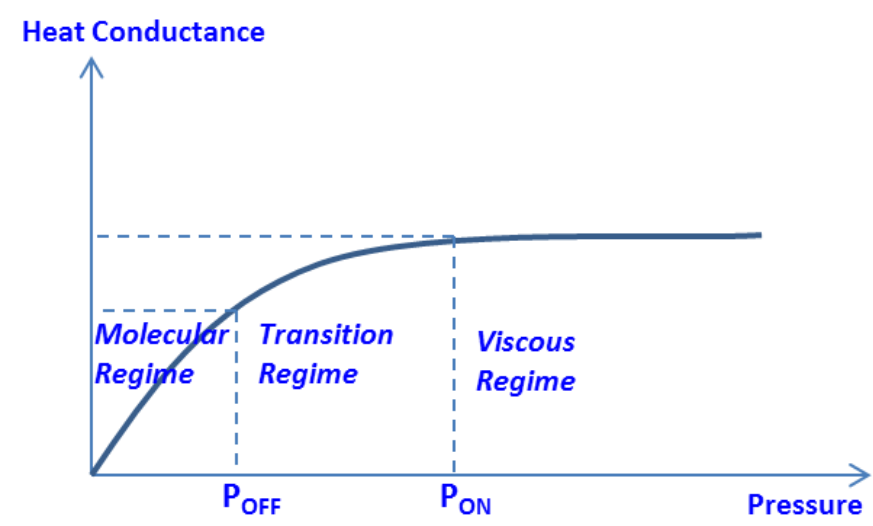

Figure 11: "ON" and "OFF" states of a Gas Gap Heat Switch, adapted from Prina et al. [64]

\subsection{Energy Systems}

\subsubsection{Battery}

Metal hydride batteries [65-70] have long been established as an effective and long lasting dc power source for electronic equipments. Rechargeable versions of such batteries especially NiMH batteries [66, $68,71,72]$ are also available commercially for applications ranging from cameras to hybrid vehicles. 
Such batteries generally have positive electrode made of nickel hydroxide, which is a very well-known electrode material for over 100 years since it has similar composition as NiCd batteries. The active material for the negative electrode is the hydrogen stored in intermetallic alloy that also serves as an electrode. Most of the batteries use $\mathrm{AB}_{2}$ or $\mathrm{AB}_{5}$ type metal hydride alloys as the negative electrode. The reversible reaction [73] that occurs in the cell manufactured by COBASYS is given as follows:

$$
\mathrm{MH}+\mathrm{OH}^{-} \leftrightarrow \mathrm{M}+\mathrm{H}_{2} \mathrm{O}+e^{-}
$$

The cell diagram for those batteries is shown in Figure 12(a) and the combined reaction that takes place inside such a cell is given as:

$$
\mathrm{MH}+\left(\mathrm{\beta}-\mathrm{NiOOH} \cdot \mathrm{H}_{2} \mathrm{O}\right) \leftrightarrow \mathrm{M}+\mathrm{Ni}(\mathrm{OH})_{2}+\mathrm{H}_{2} \mathrm{O}
$$

Here $\mathrm{MH}$ is the metal hydride, $\beta-\mathrm{NiOOH}$ is a low conductivity $p$-type semiconductor when nickel valance is less than 2.25. Because of the performance and robustness offered by the NiMH battery technology, the application realm has been extended to hybrid electric vehicles especially requiring high power performance, cycling and operation life [70]. Most of the research related to this maturing technology is focused on characterization of negative electrode material (metal hydride) and properties enhancement methods for positive electrode [71].

a)

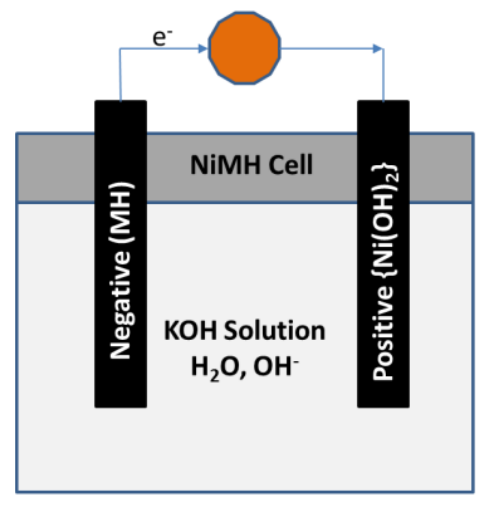

b)

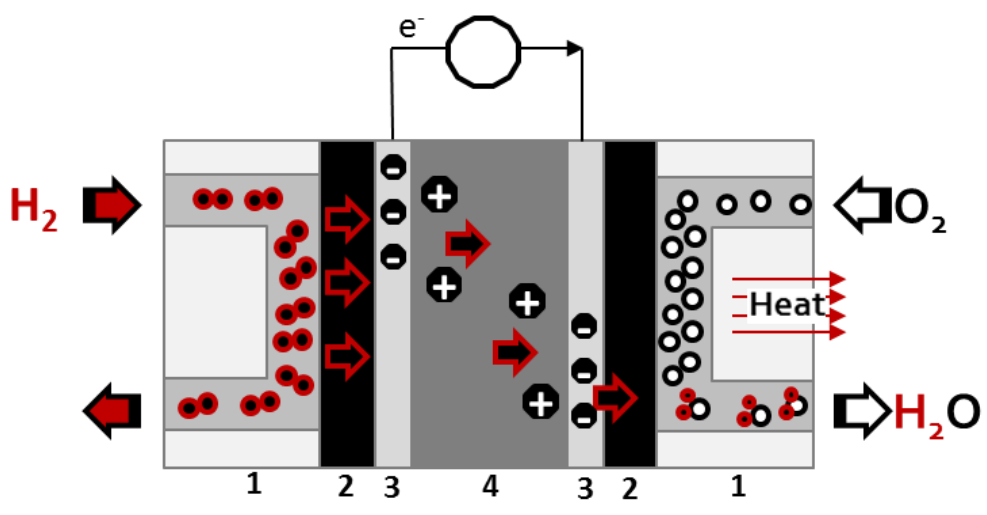

Figure 12: a) COBASYS NiMH battery cell diagram, adapted from Kopera [73], b) Proton exchange membrane (PEM) fuel cell, adapted from ART [74]

\subsubsection{Fuel Cell}

Fuel cells, on the other hand, are devices that transform stored chemical energy into usable electrical energy with water and heat as byproducts. For hydrogen based fuel cells [86] the chemical energy comes from hydrogen fuel stored in metal hydrides. It reacts with oxygen to create electricity by an electrochemical process. Among various types of fuel cells polymer exchange membrane (PEM) fuel cell $[75,76]$ is most likely a candidate to see vehicular application. Such cells are expected to replace the 
internal combustion engines by generating DC power to drive the electric motor of a vehicle. As shown in Figure 12(b), a basic PEM fuel cell contains an anode which is typically coated with catalyst that helps free electron from hydrogen molecules. These electrons flow in the external circuit to provide electricity for the load connected to the circuit. The proton exchange membrane serves as an electrolyte. Catalyst coated positive electrode, the cathode, exposes hydrogen ion in the electrolyte to oxygen and as a result water molecules are formed. A single cell can produce about 0.7 volts [74] which can be multiplied by stacking a series of cells for practical purpose. One of the present challenges for this technology is to store enough gaseous hydrogen for the fuel cell. Metal hydrides come handy here because they can store hydrogen in solid state and can supply "on demand" hydrogen to the PEM.

\subsection{Actuation and Sensing}

\subsubsection{Hydrogen Powered Actuator}

Metal hydride integrated hydrogen powered actuators have been proposed in several studies [80-87]. The basic working principal is similar to that of the heat engine described previously. The desorbed pressurized gas is the driving force for the actuator. Since the storage density of the material is very high, compact storage medium in the system desorbs tremendous amount of hydrogen at an elevated temperature, which pressurizes the system that may comprise of piston-cylinder assembly, cylinder with metal bellow, artificial muscles, among others. Nevertheless, the fundamental operating principal remains the same. Ken Kurosaki et al. [83] designed and investigated an actuator with a cylindrical metal bellow as a functional part which is powered by copper plated $\mathrm{LaNi}_{5}$ storage system. They used a Peltier element to cyclically heat and cool the storage material for generating forward and reverse stroke in the actuation rod loaded with $10 \mathrm{~kg}$ mass. The actuation behavior of their system is shown in Figure 13(a), where the alternation of electric power to the Peltier element caused heating and cooling of the storage material which eventually causes desorption and absorption of hydrogen into the material. They claim that 10 grams of $\mathrm{LaNi}_{5}$ in their actuator can easily lift $20 \mathrm{Kg}$ load with the displacement of $80 \mathrm{~mm}$. The velocities for the forward and return stroke are about $2.3 \mathrm{~mm} / \mathrm{s}$ and $1.6 \mathrm{~mm} / \mathrm{s}$, respectively. The efficiency of their system was calculated to be less than $1 \%$. A similar system has been developed by Vanderhoff et al [81], which comprises of a braided 
pneumatic artificial muscle. The performance of the braided pneumatic muscle has also been compared with different types of actuators in terms of stress vs. strain generated as shown in Figure 13(b). The performance of such a system was found to be very much comparable with the biological muscle. It was also pointed out that the performance realm could be extended to a broader horizon by improving the design or by using a high capacity metal hydride for storage. It has been claimed that this system has a relatively good $2^{\text {nd }}$ law efficiency, which is about $30 \%$ over the desorption cycle. Nevertheless, the system showed comparable work output and biological muscle like properties, which makes it suitable for robotic applications.

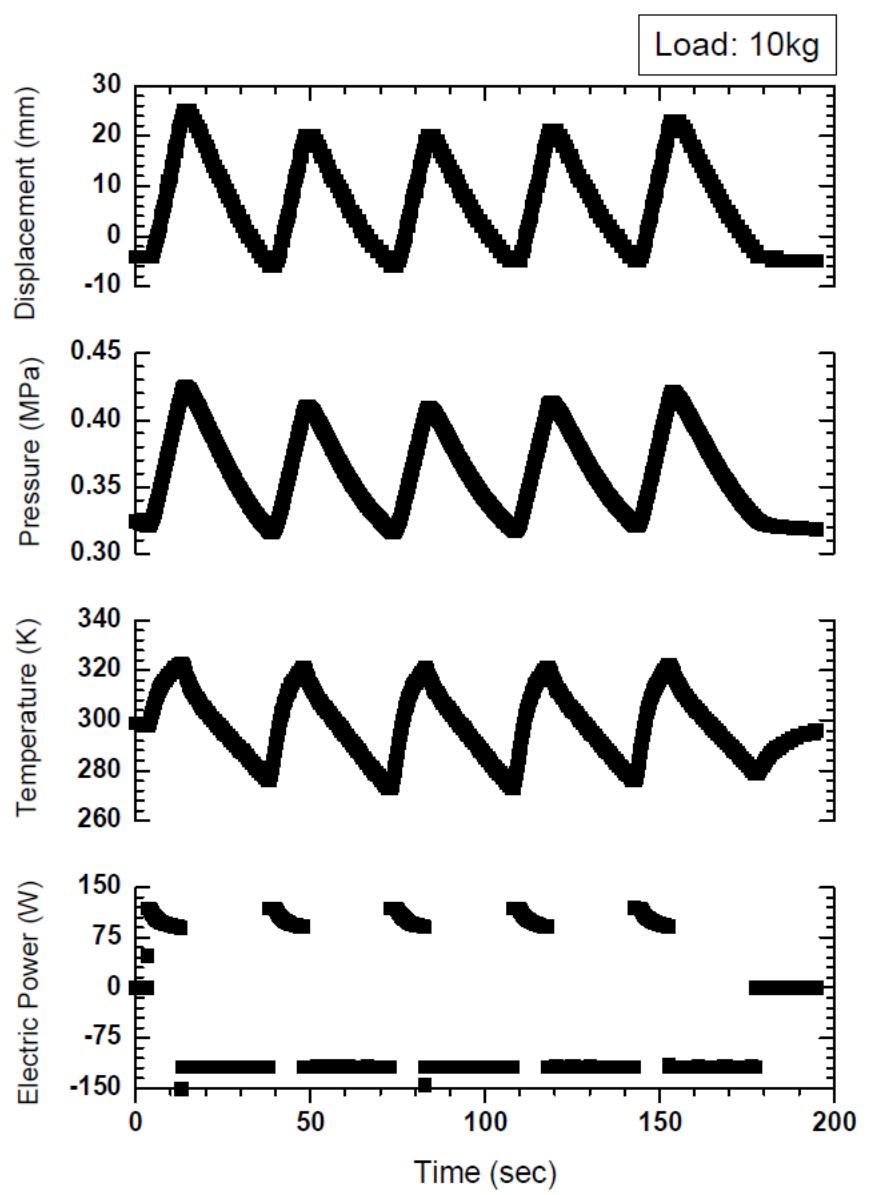

(a)
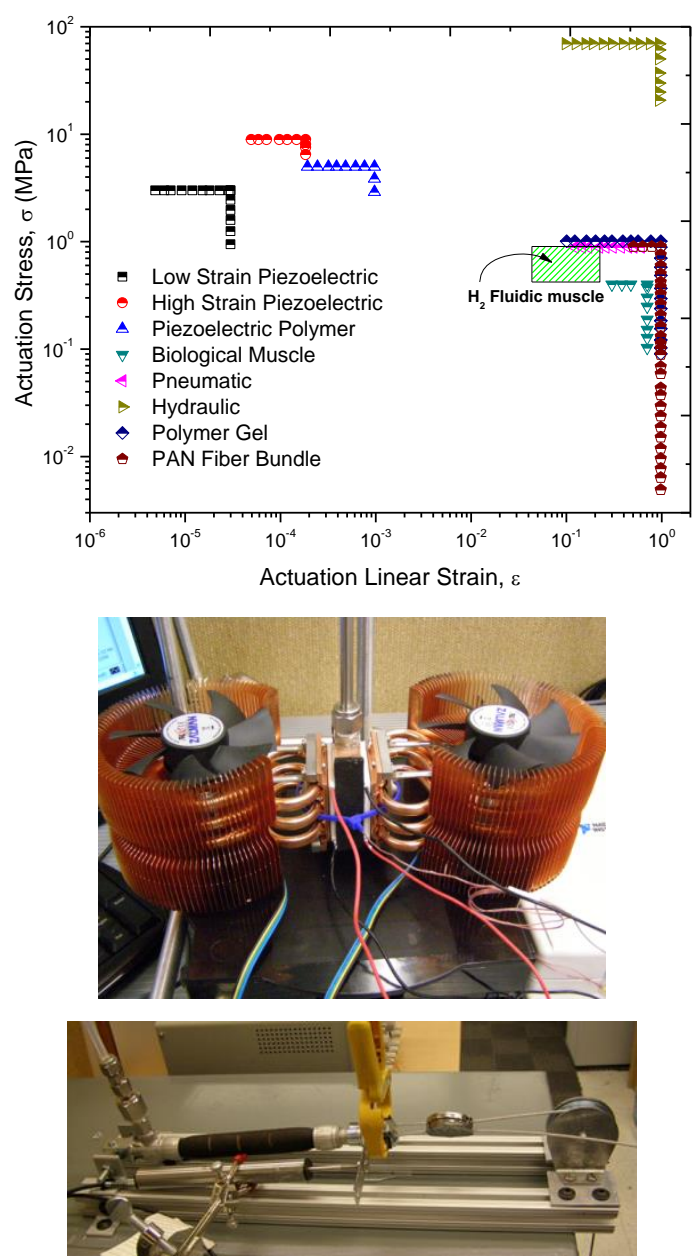

(b)

Figure 13: a) Actuation characteristics of metal hydride actuator, reprinted with permission from Kurosaki et al [83]

b) top-Actuation device comparison of stress vs. linear strain, adapted from, adapted from Vanderhoff [81] and Choe et al. [88]; middle-a photography of metal hydride reactor; bottom-a photography of the actuator 


\subsubsection{Hydrogen Gas Sensor}

The change in optical, electrical properties, and lattice expansion of some hydrides, in presence of hydrogen, makes them suitable for hydrogen sensing applications [89, 92]. Metal hydride thin films on MEMS based micro-hotplate [89] have been developed for hydrogen sensing applications. A palladium coated rare earth thin metal film, in this case, changes the electric resistivity in the presence of hydrogen. The rare earth thin film reacts with hydrogen after which the electrical resistivity increases several orders of magnitude. Thus, such types of hydrogen sensors are highly sensitive and have been reported to have less than half a second response time with $0.25 \%$ hydrogen concentration. Figure 14 shows how this system responds to the changing concentration of hydrogen. The response time was found to be as low as $0.44 \mathrm{~s}$ when the micro-hotplate was kept at $50-80^{\circ} \mathrm{C}$ by passing less than $5 \mathrm{~mA}$ current through the embedded heater element. The response time, however, was reported to be slower at room temperature. A fiber optic hydrogen gas sensor made with Pd-capped chemo chromic metal hydride sensing layer [90] has also been investigated for sensing application. In this study, the reflectance of $\mathrm{Mg}$ based hydrogen alloys were reported to reduce by a factor of 10 within a few seconds with a hydrogen level of $15 \%$ or lower. A differential capacitive thin film sensor [92] has recently been proposed for hydrogen sensing application, which works based on the lattice expansion of $\mathrm{LaAl}_{0.3} \mathrm{Ni}_{4.7}$. It was found that the lattice expansion was proportional to the partial pressure of hydrogen over the range of 0.01-1.3 atm.

\subsubsection{Smart Windows:}

Optical properties of some complex hydride have been discovered to be similar to semiconductors [91], which paved the path towards the application of hydrides as antireflection coatings. The concept of smart window using hydrides was first developed after the switchable optical properties of yttrium hydride and lanthanum hydride films were discovered [93]. Transparent yttrium hydride thin films prepared by magnetron sputter deposition were found to have transparent behavior with higher partial pressure of hydrogen [94]. The crystal structure of the transparent film was reported to have fcc lattice instead of hcp in the study. André Anders et al. investigated electrochromically switched energy efficient mirror [95] for smart window application. In this study electrochromic mirror using MnNiMg was prepared for proof of the concept experiments, which operates by the application of small voltage that drives the electrochemical change. Nevertheless, these layers of hydride may also be switched gasochromically, which is accomplished by hydrogenation of the layer making the coat transparent and dehydrogenation of the layer making the coat reflective. Figure 15(a) shows the miniature insulated 
glass unit prepared for the investigation. This study concentrated on the switching performance and durability of the system. As shown in Figure 15(b), the dynamic spectral reflectance was quantified as a function of wavelength. While the coat is in hydride state, reflectance is high. While the coat is dehydrated, on the other hand, the window becomes light transmitting and the reflectance drops down to below $10 \%$ for most ranges of the wavelengths. The varying transmittance and reflectance as a function of wavelength is advantageous for over all energy saving efficacy of switchable smart windows.
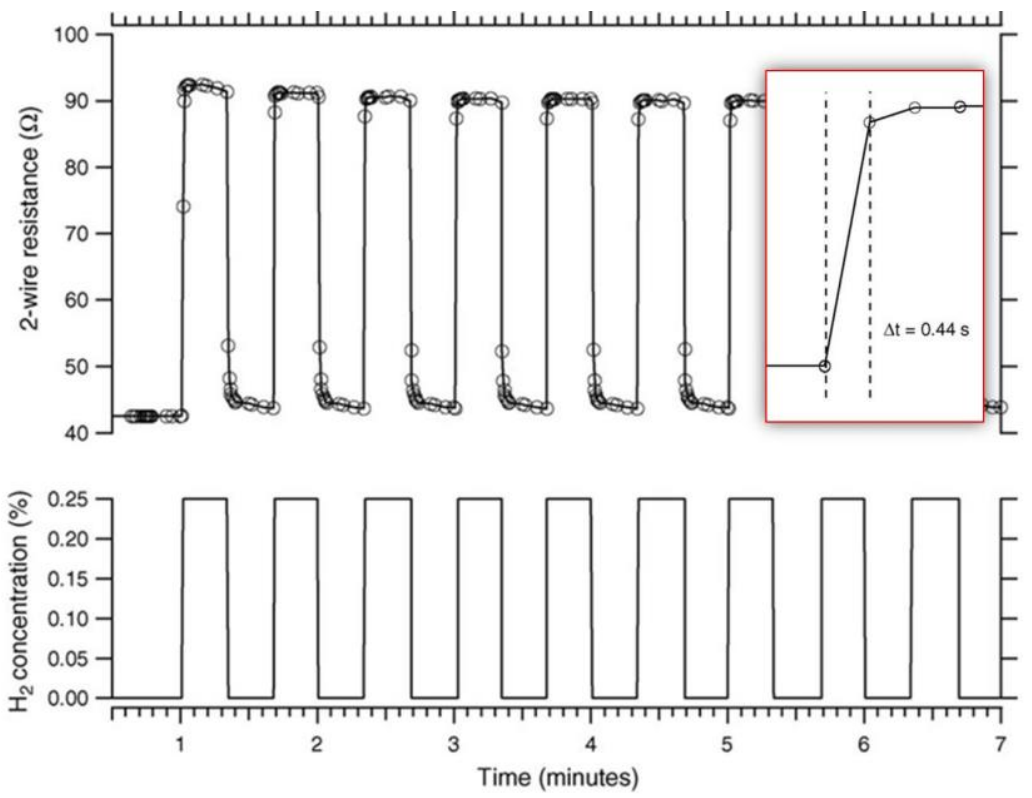

Figure 14: Micro-hotplate based hydrogen gas sensor response for repeated exposure to $0.25 \% \mathrm{H}_{2}$ in air with less than half second response time, reprinted with permssion from Frank DiMeo et al. [89].

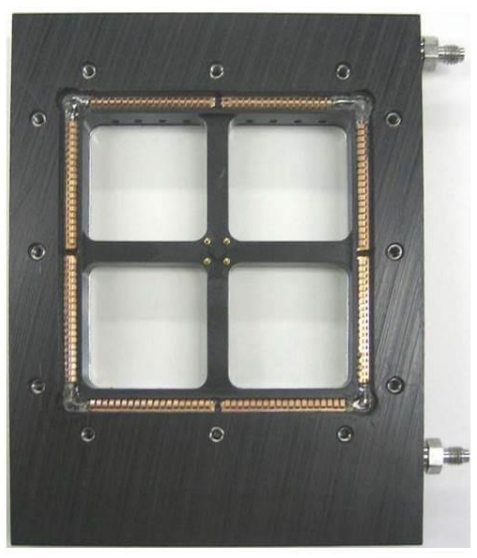

(a)

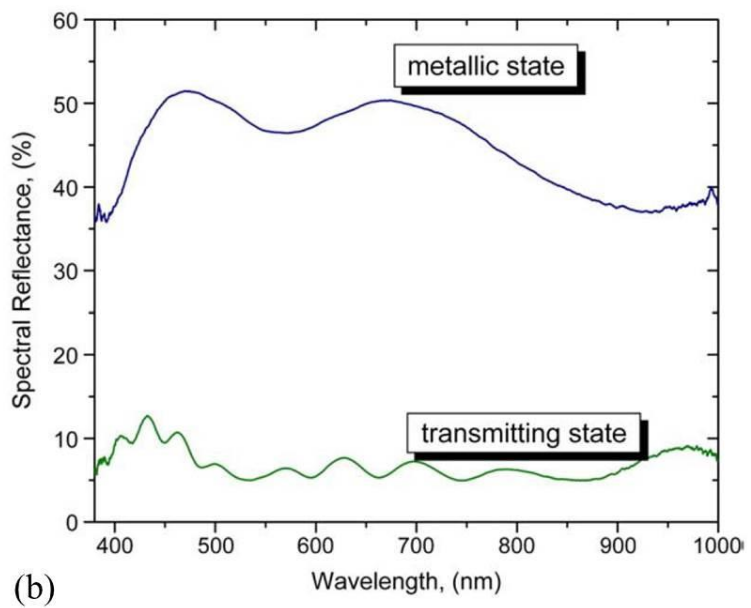

(b)

Figure 15: (a) Test window unit, and (b) spectral reflectance and transmittance, reprinted with permission from Anders et al. [95] 


\subsection{Processes}

\subsubsection{Purification}

Purification of hydrogen by absorbing hydrogen in metal hydrides from a mix of gases and subsequently pressurizing the container with purified hydrogen to drive out the unwanted gases is a common technique for purification of hydrogen [96-98].One of the earliest demonstrations of purification process was reported by Block et al. [96] where the concept described above was applied. Later $\mathrm{FeTi}_{0.95} \mathrm{Mm}_{0.08}$ based hydrogen purification system [99] was reported to operate within temperature range of $25-90{ }^{\circ} \mathrm{C}$ and yielding a $99.99999 \%$ purity of hydrogen excluding vapor content. In a recent study, metal hydride based hydrogen purification and storage system was investigated by Shinichi Miura et al. [100]. They incorporated carbon monoxide removal unit in the preliminary step of purification. Carbon monoxide forms a barrier layer on the surface of metal hydride and basically kills its ability to absorb and store hydrogen. Hence, in the initial stage of purification this poisonous gas is removed by incorporating special carbon monoxide absorbent. Next, the gas mixture is introduced to metal hydride where only the hydrogen is absorbed and stored for future use. This method has been referred to as Carbon Monoxide Adsorption Metal Hydride IntermediateBuffer (COA-MIB). The setup used to carry out the process is shown in Figure 16. Here, Carbon Monoxide Pressure Vacuum Swing Adsorption (CO-PVSA) method was used to eliminate carbon monoxide.

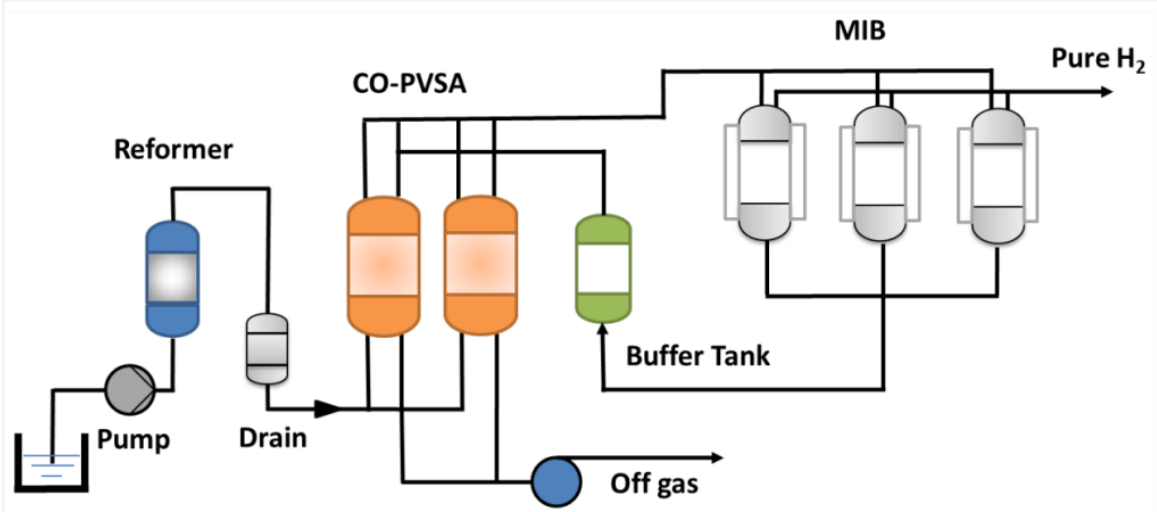

Figure 16: Process flow diagram of the purification system, adapted from Miura et al. [100] 
The system utilized $A B_{5}$ type hydrogen storage material and operates from 20 to $80{ }^{\circ} \mathrm{C}$. After 150 hours of daily start and stop operation, this $100 \mathrm{NL} / \mathrm{h}$ laboratory scale apparatus was able to attain $83 \%$ hydrogen recovery ratio defined as,

$$
\text { Hydrogen recovery ratio }=\frac{\text { Amount of hydrogen absorption }}{\text { Amount of hydrogen put into the system }} \times 100
$$

Figure 17 shows the purity of the hydrogen and measured ppm of carbon monoxide with time for the system discussed. The switching was done every half an hour, which caused to increase the $\mathrm{CO}_{2}$ concentration because of the fact that the residual gas was not being purged completely. Impurities other than $\mathrm{CO}_{2}$ were not found in the final product and it was confirmed that the level of $\mathrm{CO}_{2}$ was as high as $1 \%$ immediately after switching. Even though, the level of $\mathrm{CO}_{2}$ drops below 1000 ppm within 15 minutes, further development may be done on this system considering the required purity level of hydrogen in the final product prescribed by ISO for fuel cell applications.

\subsubsection{Isotope separation}

Metals such as Palladium preferably absorb protium more than heavier deuterium and tritium from a mixture of isotopes of hydrogen. This tendency is more prominent at reduced temperature [101]. $\mathrm{LaNi}_{4.25} \mathrm{Al}_{0.25}$, on the other hand, absorbs tritium more at low temperatures with reversing effect (absorbing lighter deuterium and protium) at temperature above $40^{\circ} \mathrm{C}$ [102]. Such properties of metal hydrides are very useful for designing isotope separation processes [103-105] for industrial applications. Ito et al. investigated the influence of magnetic field in separation of deuterium from protium using ferromagnetic $\mathrm{LaCO}_{5}$ and paramagnetic $\mathrm{LaNi}_{5}$ as storage material. The dependency of equilibrium pressure of ferromagnetic hydride under magnetic field $B$ is given as [105],

$$
P_{B}=P_{0} \exp \left(\frac{2 B \Delta M_{S}}{R T}\right)
$$

Here, $P$ is the equilibrium pressure, $\Delta M_{S}$ is the change in the saturation magnetization per mole of desorbed hydrogen, $R$ is the ideal gas constant and $T$ is the temperature. Since the equation above is dependent on the change in saturation magnetization of the storage material under the influence of applied magnetic field $B$, paramagnetic materials such as $\mathrm{LaNi}_{5}$ are not expected to show notable change in separation performance. Ferromagnetic materials like $\mathrm{LaCO}_{5}$, however, will show improvement in equilibrium pressure under the effect of magnetic field since there will be a significant change in saturation magnetization in the material. The assumption made in this study is that the separation ability is related to equilibrium pressure difference $P^{\mathrm{D}}-P^{H}$, which can be further enhanced under the influence of magnetic field for a ferromagnetic hydrogen storage material. 1:1 mix of protium and 
deuterium is introduced into the reactor containing the storage material, which is placed in the center of the cryo-cooled supper conducting magnet as shown in Figure 18(a). The concentration of protium/deuterium concentration was measured with a mass spectrometer. As shown in Figure 18(b), deuterium concentration increased with increasing magnetic field for the $\mathrm{LaCO}_{5}$ system. This effect is more significant for $\beta+\gamma$ region than $\alpha+\beta$ region. One of the measures for isotope separation ability of hydride is the isotope separation factor $\alpha$, defined as:

$$
\alpha=\frac{(D / H)_{\text {gas }}}{(D / H)_{\text {solid }}}
$$

The isotope separation ability increases as $\alpha$ deviates from unity. Ito et al reported that this separation factor can be increased about $46 \%$ under the influence of magnetic field at $13 \mathrm{~T}$ using ferromagnetic $\mathrm{LaCO}_{5}$ metal hydrides.

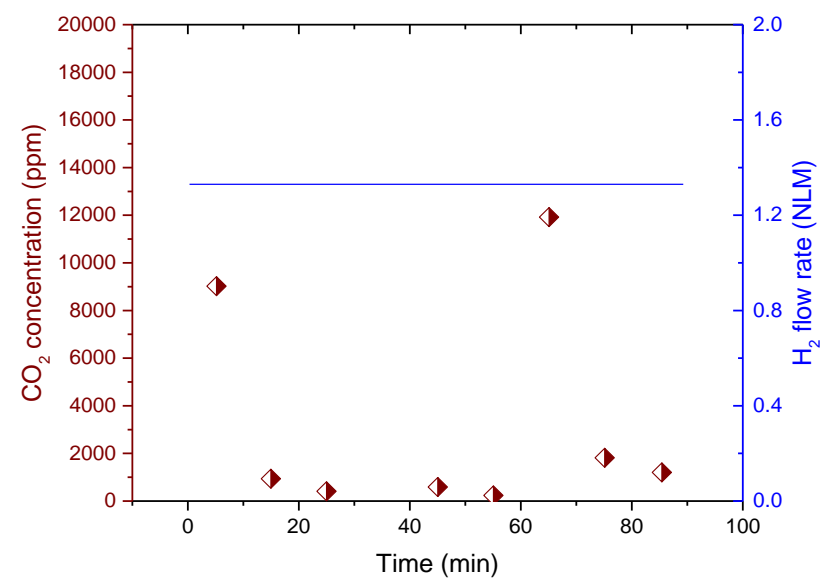

Figure 17: Purity of the final product as a function of hydrogen flow rate, adapted from Miura et al.

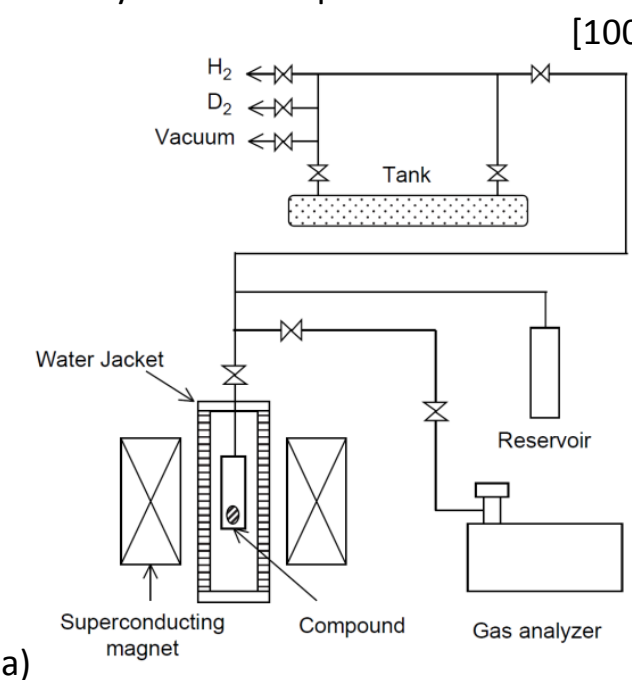

100]

a)

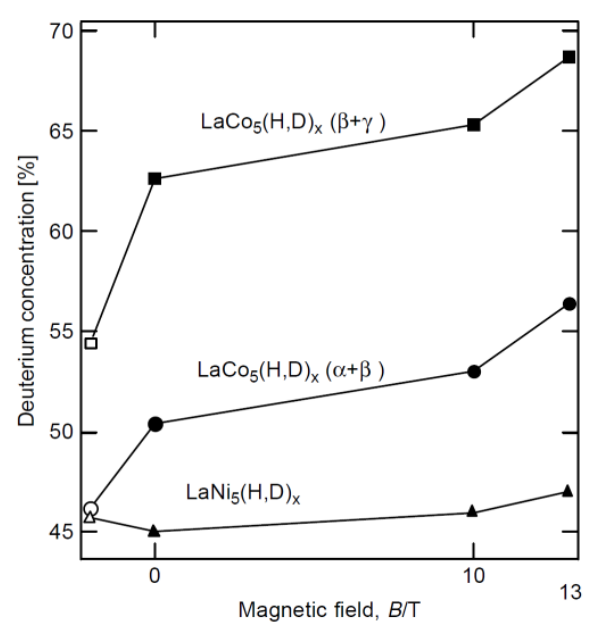

Figure 18: a) schematic diagram of isotope separation setup, and b) effect of magnetic field in separation process. Reprint with permission from Ito et al. [105] 


\subsubsection{Catalysis}

Some metallic hydrides are very reactive in nature. This behavior of hydrides has been successfully exploited for the application of hydrides as catalysts. Mimoun [106] used zinc hydride catalysts for the reduction of methyl benzoate, aldehydes, ketones, esters, triglycerides, and epoxides to alcohols by polymethylhydrosiloxane (PMHS). The zinc hydride catalysts were produced by the reaction of soluble metal carboxylates with sodium borohydride. Mimoun also found that zinc hydride efficiently catalyzes the dehydrogenative hydrosilylation of alcohols. Pez et al. [107] and Grey et al. [108] developed anionic metal hydrides for catalysis. They synthesized potassium hydrido(phospine)ruthenate complexes: (1) $\mathrm{K}^{+}\left[\left(\mathrm{Ph}_{3} \mathrm{P}\right)_{2} \mathrm{Ph}_{2} \mathrm{PC}_{6} \mathrm{H}_{4} \mathrm{RuH}_{2}\right] \cdot \mathrm{C}_{10} \mathrm{H}_{8} \cdot\left(\mathrm{C}_{2} \mathrm{H}_{5}\right)_{2} \mathrm{O}$ and (2) $\mathrm{K}^{2+}\left[\left(\mathrm{Ph}_{3} \mathrm{P}\right)_{3}\left(\mathrm{Ph}_{2} \mathrm{P}\right) \mathrm{RuH}_{4}\right]^{2-} \cdot 2 \mathrm{C}_{6} \mathrm{H}_{14} \mathrm{O}_{3}$ and explored their roles in the hydrogenation of polar organic solvents. The complex (1) $\mathrm{K}^{+}\left[\left(\mathrm{Ph}_{3} \mathrm{P}\right)_{2} \mathrm{Ph}_{2} \mathrm{PC}_{6} \mathrm{H}_{4} \mathrm{RuH}_{2}\right]$ . $\mathrm{C}_{10} \mathrm{H}_{8} .\left(\mathrm{C}_{2} \mathrm{H}_{5}\right)_{2} \mathrm{O}$ was prepared reacting $\left(\mathrm{Ph}_{3} \mathrm{P}\right)_{3} \mathrm{RuHCl} . \mathrm{C}_{6} \mathrm{H}_{5} \mathrm{CH}_{3}$ with potassium naphthalene. The complex (2) $\mathrm{K}^{2+}\left[\left(\mathrm{Ph}_{3} \mathrm{P}\right)_{3}\left(\mathrm{Ph}_{2} \mathrm{P}\right) \mathrm{RuH}_{4}\right]^{2-} .2 \mathrm{C}_{6} \mathrm{H}_{14} \mathrm{O}_{3}$ was synthesized by potassium naphthalene reduction of $\left[\left(\mathrm{Ph}_{3} \mathrm{P}\right)_{2} \mathrm{RuHCl}\right]_{2}$.2toluene. They found that both metal hydride complexes (1) and (2) facilitated the hydrogenation of ketones, aldehydes, carboxylic acid esters to alcohols and the hydrogenation of nitriles to primary amines. They further found that the complex (2) was unique in that it facilitated the homogeneous hydrogenation of aliphatic esters to the corresponding alcohols. Imamura et al. [110] studied the role of metal hydrides $\mathrm{LaNi}_{5}, \mathrm{CaNi}_{5}$, and $\mathrm{LaNi}_{4} \mathrm{Al}$ as catalysts for the hydrogenation and dehydrogenation of organic compounds. It should be noted here that the three alloys have different equilibrium pressures. They used these metal hydrides as catalysts for the dehydrogenation of cyclohexane to benzene and the subsequent hydrogenation of butene to butane.

$$
\text { Cyclohexane }\left(\mathrm{C}_{6} \mathrm{H}_{10}\right)+\text { Butene }\left(\mathrm{C}_{4} \mathrm{H}_{8}\right) \rightarrow \text { Benzene }\left(\mathrm{C}_{6} \mathrm{H}_{6}\right)+\text { Butane }\left(\mathrm{C}_{4} \mathrm{H}_{10}\right)
$$

Among the three metal hydrides used as catalysts, $\mathrm{CaNi}_{5}$ showed the best results because of its higher activity compared to $\mathrm{LaNi}_{5}$ and $\mathrm{LaNi}_{4} \mathrm{Al}$. In their experiments, cyclohexane acted as the hydrogen donor. In the presence of $\mathrm{CaNi}_{5}$, cyclohexane (21 Torr) was successfully dehydrogenated to yield benzene $\left(\mathrm{C}_{6} \mathrm{H}_{10}\right.$ $+\mathrm{CaNi}_{5} \mathrm{H}_{4} \rightarrow \mathrm{C}_{6} \mathrm{H}_{6}+\mathrm{CaNi}_{5}$ ) at $423 \mathrm{~K}$ (Figure 19). It was simultaneously converted to benzene and cyclohexane by disproportionation. $63 \%$ of the dissociated hydrogen was absorbed by $\mathrm{CaNi}_{5}$ and the rest was released as gaseous hydrogen. After the 19 hours reaction, benzene (11 Torr), cyclohexane (16 Torr), and hydrogen (6 Torr) were formed. At this point, 2-butene at 30 Torr was added to the gases. This resulted in the hydrogenation of butene to butane by the absorbed hydrogen rather than the gaseous hydrogen $\left(\mathrm{C}_{4} \mathrm{H}_{8}+\mathrm{CaNi}_{5} \rightarrow \mathrm{C}_{4} \mathrm{H}_{10}+\mathrm{CaNi}_{5} \mathrm{H}_{4}\right)$. 
A fluorinated metal hydride, $\mathrm{LaNi}_{4.7} \mathrm{Al}_{0.3}$, has been used for the production of methane from a mixture of $\mathrm{CO}_{2}$ and $\mathrm{H}_{2}$ gases [111]. The mechanisms underlying the methanation process have been illustrated schematically in Figure 20. A thin fluorinated layer is formed in the vicinity of Ni-rich layer as can be seen from Figure 20. The methanation process comprises of two steps: hydriding and dehydriding. During the hydriding phase (at $30^{\circ} \mathrm{C}$ ), hydrogen enters the alloy lattice while $\mathrm{CO}_{2}$ molecules are absorbed on the alloy surface. In the subsequent, dehydriding phase, the alloy is heated to a temperature of 150 ${ }^{\circ} \mathrm{C}$, the absorbed hydrogen is dissociated on the alloy surface and reacts with the absorbed $\mathrm{CO}_{2}$ to form methane $\left(\mathrm{CH}_{4}\right)$. This process is known as pressure-temperature swing [111].

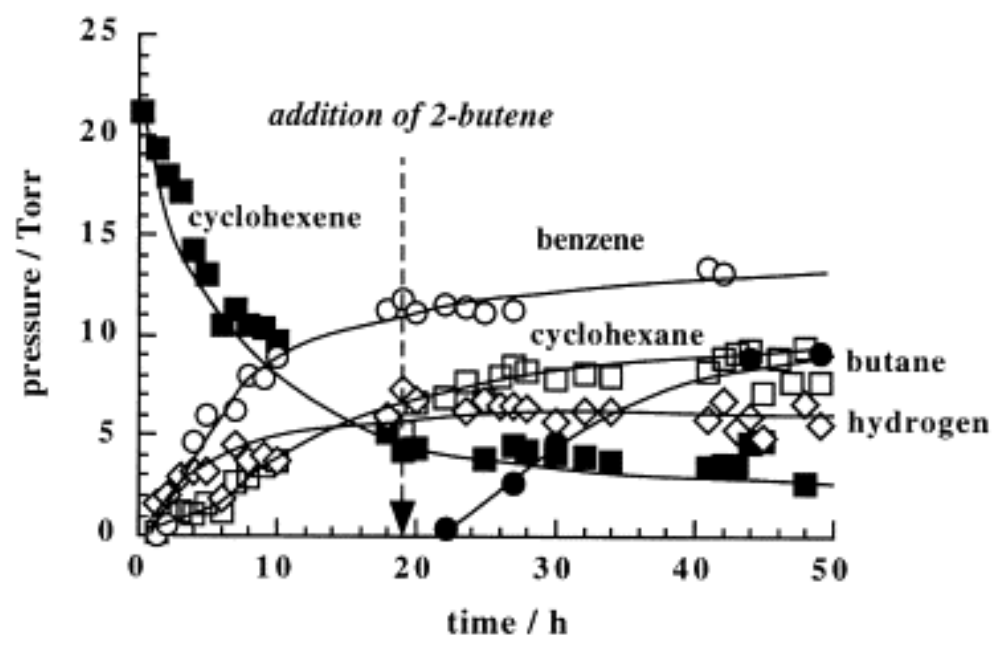

Figure 19: Pressure vs. Time plot of dehydrogenation and hydrogenation reaction at $423 \mathrm{~K}$ using $\mathrm{CaNi}_{5}$ as a catalyst, reprint with permission from Imamura et al. [110]

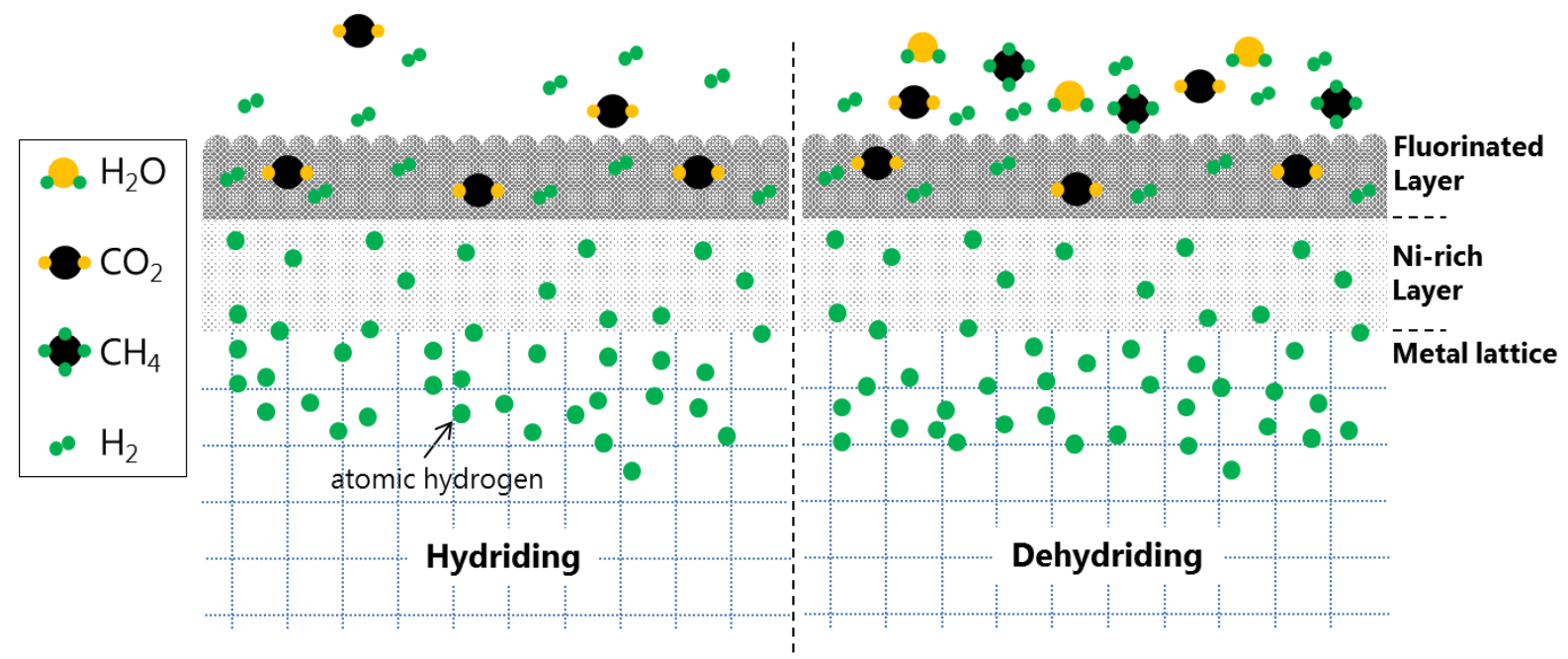

Figure 20: Hydriding and dehydriding mechanisms of fluorinated hydriding alloy, adapted from Iwata et al. [111] 


\subsection{Semiconducting Hydrides}

The band structures of some hydrides like $\mathrm{AlH}_{3}, \mathrm{KMgH}_{3}$, and others, have been analyzed by Vajeeston et al [112] using density functional theory. Several hydrides have been found to have $n$-type and $p$-type electrical conductivities as seen in semiconductor materials. They are also reported to have transparent and visible range of the optical spectrum. This adds a new class of semiconducting material with potential applications in "hydride electronics". In a later study [113], Karazhanov et al identified the features like large band gap, well dispersed bottom most conduction band, small electron/hole masses etc. as seen in semiconductor materials. Figure 21 shows the band gap of metal and complex hydrides adopted from their study. Squares and Circles represent experimental and theoretical predictions, respectively. Light background represents opaque, darker background represents transparency energy ranges. Darkest is the most desirable transparency range. Issues like interface and band gap in semiconductor have been argued to be solved by this new generation of hydride semiconductors. Complex hydrides such as $\mathrm{Be}\left(\mathrm{BH}_{4}\right)_{2}$ with slower absorption-desorption kinetics and high storage capacity (20.8\%wt) have been referred as suitable candidates for semiconductor applications because of their stability at high temperatures. Potential applications of such semiconducting hydrides are in solar cells, which are protected from the ambient by a thin layer.

\subsection{Biomimetic and Biomedical Systems}

Metal hydride integrated actuators $[85,114]$ and artificial muscles $[80,81,85,114]$ for application in biomimetic systems have been proposed and investigated by many researchers. These applications involving metal hydrides are basically related to biomimetic devices that are powered by hydrogen stored in a metal hydride. For biomedical applications, the hydride material is usually not used directly in living biological systems. Materials such as titanium can form hydrides and whose powdered state can be compacted and used in vivo since such materials are biocompatible. The process for powdering the material is, however, expensive and can be replaced by hydrogenation and dehydrogenation process, which eventually transforms the agglomerates into powder after multiple cycles of sorption. This procedure is referred as hydride-dehydride $(\mathrm{HDH})$ method. The sorption cycles with titanium in $\mathrm{HDH}$ method were adopted by Barreiro et al [115] to manufacture powders with particle sizes of 37 and 125 micron. These powders were further sintered into desired shape in order for osseointegration in the tibia bone of Wistar rat. Cylindrical Ti implants prepared from these powders were implanted inside the 
tibia bones of the rats. The study showed uneventful healing with a normal pattern of bone repair without inflammatory reaction. The histological analysis of this study was performed using microscopic analysis of the behavior of bone tissues in contact with the metal. The study shows that the microscopic images of the bone in contact with metalon the $60^{\text {th }}$ day post-implantation. This investigation indicates biocompatibility of titanium prepared by $\mathrm{HDH}$ process followed by compaction using high pressure sintering. The process is economic and no difference has been observed for compaction and sintering behavior for materials prepared by $\mathrm{HDH}$ process as compared to the commercially available titanium powders. In a nutshell, this study demonstrated indirect application of metal hydrides in a living biological system.

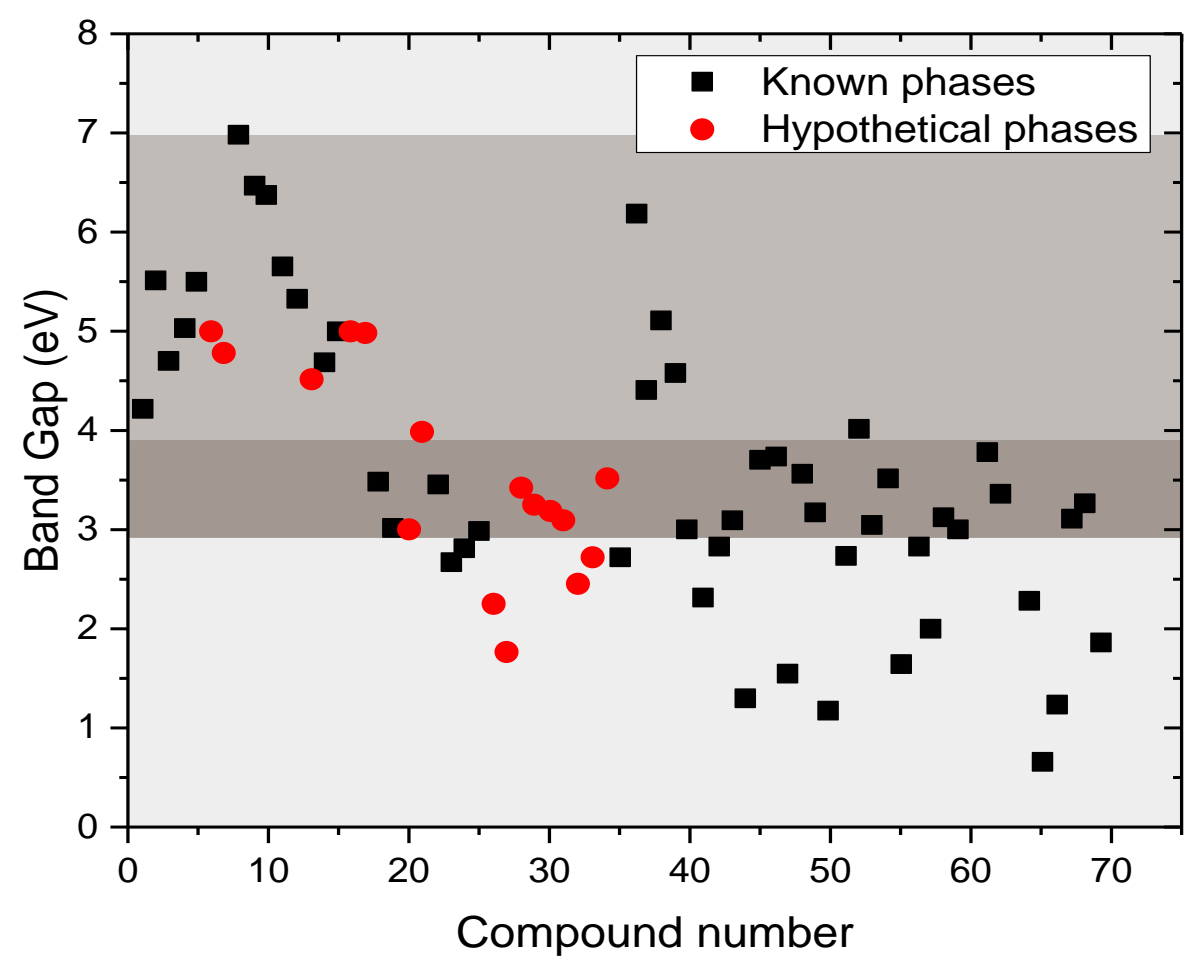

Figure 21: Band gap of metal and complex hydrides adapted from Karazhanov et al[113]: (1-4) $\mathrm{MgH}_{2}$, $\mathrm{BeH}_{2}, \mathrm{LiAlH}_{4}, \mathrm{NaAlH}_{4}$; (5-9) $\mathrm{KAlH}_{4}, \mathrm{RbAlH}_{4}, \mathrm{CsAlH}_{4}, \mathrm{LiBH}_{4}, \mathrm{NaBH}_{4}$; (10-14) KBH $4, \mathrm{RbBH}_{4}, \mathrm{CsBH}_{4}, \mathrm{LiGaH}_{4}$, $\mathrm{NaGaH}_{4}$; (15-19) $\mathrm{KGaH}_{4}, \mathrm{RbGaH}_{4}, \mathrm{CsGaH}_{4}, \mathrm{Li}_{3} \mathrm{AlH}_{6}, \mathrm{Na}_{3} \mathrm{AlH}_{6}$; (20-24) $\mathrm{K}_{3} \mathrm{AlH}_{6}, \mathrm{LiMgH}_{3}, \mathrm{NaMgH}_{3}, \mathrm{KMgH}_{3}$, $\mathrm{RbMgH}_{3}$; (25-29) $\mathrm{CsMgH}_{3}, \mathrm{LiBeH}_{3}, \mathrm{NaBeH}_{3}, \mathrm{KBeH}_{3}, \mathrm{RbBeH}_{3}$; (30-34) $\mathrm{SBeH}_{3}, \mathrm{BeAlH}_{5}, \mathrm{MgAlH}$, CaAlH $\mathrm{SrAlH}_{5}$; (35-39) $\mathrm{BaAlH}_{5}, \mathrm{MgB}_{2} \mathrm{H}_{8}, \mathrm{MgAl}_{2} \mathrm{H}_{8}, \mathrm{CaB}_{2} \mathrm{H}_{8}, \mathrm{CaAl}_{2} \mathrm{H}_{8}$; (40-44) $\mathrm{Ba}_{6} \mathrm{Mg}_{7} \mathrm{H}_{26}, \mathrm{BaMgH}_{4}, \mathrm{Ca}_{19} \mathrm{Mg}_{8} \mathrm{H}_{54}$, $\mathrm{Ca}_{4} \mathrm{Mg}_{3} \mathrm{H}_{14}, \mathrm{Ca}_{4} \mathrm{Mg}_{4} \mathrm{FeH}_{63}$; (45-49) $\mathrm{CaMgNiH}_{4}, \mathrm{Cs}_{2} \mathrm{MgH}_{4}, \mathrm{Cs}_{3} \mathrm{MgH}_{5}, \mathrm{~K}_{2} \mathrm{MgH}_{4}, \mathrm{LiMg}_{2} \mathrm{RuH}_{6}$; (50-54) $\mathrm{Mg}_{2} \mathrm{RuH}_{4}$, $\mathrm{Mg}_{3} \mathrm{ReH}_{7}, \mathrm{Rb}_{2} \mathrm{MgH}_{4}, \mathrm{Rb}_{3} \mathrm{MgH}_{5}, \mathrm{Rb}_{4} \mathrm{Mg}_{3} \mathrm{H}_{10}$; (55-59) $\mathrm{SrMg}_{2} \mathrm{FeH}_{8}, \mathrm{SrMgH}_{4}, \mathrm{SrMgNiH}_{4}, \mathrm{Yb}_{4} \mathrm{Mg}_{3} \mathrm{H}_{14}, \mathrm{Sr}_{2} \mathrm{Mg}_{3} \mathrm{H}_{10}$; (60-65) LiH, NaH, KH, RbH, CsH, CuH; (66-69) $\mathrm{BaLiH}_{3}, \mathrm{CaCaH}_{3}, \mathrm{RbCaH}_{3}, \mathrm{SrLiH}_{3}$; (70-72) $\alpha-\mathrm{AlH}_{3}, \beta-\mathrm{AlH}_{3}, \mathrm{Y}^{-}$ $\mathrm{AlH}_{3}$. 


\subsection{Recent Development in Nuclear Engineering}

Application of metal hydride in nuclear engineering has been proposed as neutron absorber back in 1973 by R. V. Houten [116]. Boron carbide $\left(B_{4} C\right)$ is typically used as a neutron absorber, which generates helium gas and has a short life. Recently (2012) Konashi et al [117] envisioned a new material that would increase transmutation rate without generating helium gas for environmentally benign nuclear applications. In the latter study, hydrides were proposed and investigated for application in nuclear reactor cores. Based on the fact that hydrogen atoms in hydride can efficiently moderate fast neutrons, Konashi et al suggested that hafnium hydride can be used in reactor cores, which can absorb three times more neutrons per atom than $\mathrm{B}_{4} \mathrm{C}$. Also, it does not generate helium gas in the process as shown in Figure 22. After performing the irradiation test on $\mathrm{Hf}$ hydride neutron absorber, the capsule was investigated using X-ray computed tomography. It was found intact and no swelling was found in the disk, which is highly desired for mechanical integrity of the system. Nuclear power plants also generate a high level of radioactive long lived minor actinides (MAs) whose transmutation is achieved by irradiation. This study also suggested actinide hydride fuels containing ${ }^{237} \mathrm{~Np},{ }^{241} \mathrm{Am}$ and ${ }^{243} \mathrm{Am}$ as a transmutation target of long lived nuclear wastes.

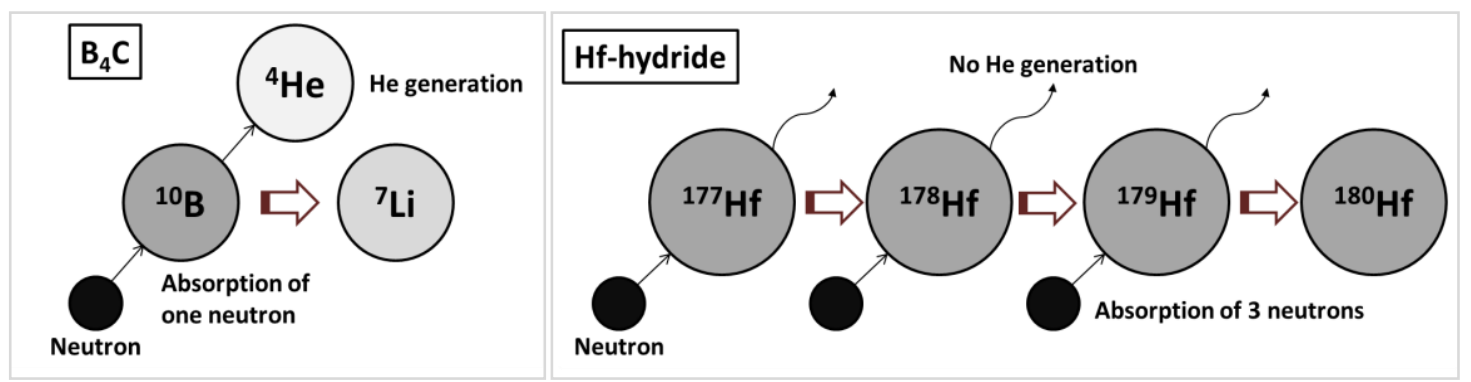

Figure 22: Neutron absorption in $\mathrm{B}_{4} \mathrm{C}$ and $\mathrm{Hf}$-hydride. Adapted from Konashi et al. [117]

\section{Conclusions}

Metal hydrides have been studied, proposed and demonstrated for numerous engineering applications as discussed throughout this article. Table 1 summarizes all such non-storage applications and properties of metal hydrides that have been exploited in those proposed applications and demonstrated prototypes. Hydride materials originally received attention from the research community because of the ability to store hydrogen at extraordinarily high density levels. It is this last quality, the storage capacity of metal hydrides, which had been coupled with most of the proposed engineering systems to generate the desired output. Utilizing the heat evolved and absorbed during the reaction process, thermal 
systems such refrigerator, heat pump, heat storage have been demonstrated to perform at satisfactory level using laboratory scale models. In some cases, the physical properties of the materials are utilized in designing applications such as sensors. The potential of metal hydrides in engineering processes and devices is immense. The implementation and commercialization of such technologies will require applicable codes and safety standards that need to be addressed once metal hydrides find their application in hydrogen powered systems in the future. The task is challenging, but nonetheless interesting and imbued with possibilities.

Table 1: Hydride features and corresponding applications

\begin{tabular}{|l|l|l|}
\hline \multicolumn{1}{|c|}{$\begin{array}{c}\text { Applications } \\
\text { Areas }\end{array}$} & \multicolumn{1}{|c|}{ Hydride Features Utilized } & Engineering Systems \\
\hline $\begin{array}{l}\text { Thermal } \\
\text { Systems }\end{array}$ & $\begin{array}{l}\text { - High storage capacity } \\
\text { - Reversible reaction during sorption process involving heat }\end{array}$ & $\begin{array}{l}\text { Compressor, } \\
\text { refrigeration, heat } \\
\text { pump, heat storage, } \\
\text { thermal engine, } \\
\text { sorption cryocooler, } \\
\text { gas gap heat switch }\end{array}$ \\
\hline Energy Systems & $\begin{array}{l}\text { - Hydrogen storage } \\
- \text { Hydrogen supply at moderate pressure from certain hydrides }\end{array}$ & Battery, fuel cells \\
\hline $\begin{array}{l}\text { Actuation and } \\
\text { Sensing }\end{array}$ & $\begin{array}{l}\text { - Reversible high pressure hydrogen supply } \\
- \text { Temperature variation in presence of gas } \\
- \text { Ability of certain hydrides to switch between transparency to } \\
\text { opacity in presence or absence of hydrogen }\end{array}$ & $\begin{array}{l}\text { Actuators, gas } \\
\text { sensors, smart } \\
\text { windows }\end{array}$ \\
\hline Process & $\begin{array}{l}- \text { Reacting with hydrogen and forming hydride when exposed } \\
\text { to a mixture of gases } \\
- \text { Absorption preference of certain metals to certain isotopes } \\
\text { of hydrogen, eg. Palladium preferably absorbs protium than } \\
\text { heavier deuterium }\end{array}$ & $\begin{array}{l}\text { Hz purification, } \\
\text { isotope separation, } \\
\text { catalysis }\end{array}$ \\
\hline Semiconductors & $\begin{array}{l}\text { - Electrical conductivity of several hydrides similar to } n \text {-type } \\
\text { and } p \text {-type conductivities of semiconductors }\end{array}$ & $\begin{array}{l}\text { Semiconducting } \\
\text { hydrides for 'hydride } \\
\text { electronics' }\end{array}$ \\
\hline Biomedical & $\begin{array}{l}\text { - Powder formation by repeated hydrogenation and de- } \\
\text { hydrogenation } \\
\text { - Biocompatibility of such process }\end{array}$ & $\begin{array}{l}\text { Pre-processing of } \\
\text { implant material } \\
\text { preparation }\end{array}$ \\
\hline Nuclear & $\begin{array}{l}\text { - High transmutation capability without generating helium gas } \\
\text { Neutron moderator, } \\
\text { transmutation }\end{array}$ \\
\hline
\end{tabular}




\section{References}

[1] Bowman Jr., R. C., and Sandrock, G., Nov. 16-20, 2003, "Metal Hydrides for Energy Storage and Conversion Applications" Proceedings of GLOBAL 2000 Atoms for Prosperity, American Nuclear Society meeting, New Orleans, LA

[2] Mueller, W. M., Blackledge, J. P., and Libowitz, G. G., 1968, "Metal Hydrides," Academic Press, New York

[3] Sandrock, G., 1999, A panoramic overview of hydrogen storage alloys from a gas reaction point of view," Journal of Alloys and Compounds, 293-295 pp. 877-888

[4] Schlapbach, L., and Zuttel, A., 2001, "Hydrogen-Storage Materials for Mobile Applications," Nature, 414(6861) pp. 353-358.

[5] Chandra, D., Reilly, J., and Chellappa, R., 2006, "Metal Hydrides for Vehicular Applications: The State of the Art," JOM, 58(2) pp. 26-32.

[6] Schuth, F., Bogdanovic, B., and Felderhoff, M., 2004, "Light Metal Hydrides and Complex Hydrides for Hydrogen Storage," Chemical Communications, pp. 2249-2258.

[7] Feng, Z., Deyou, B., Lijun, J., 1995, "Metal Hydride Compressor and its Application in Cryogenic Technology," Journal of Alloys and Compounds, 231(1-2) pp. 907-909.

[8] Hopkins, R. R., and Kim, K. J., 2010, "Hydrogen Compression Characteristics of a Dual Stage Thermal Compressor System Utilizing LaNi5 and $\mathrm{Ca} 0.6 \mathrm{Mm} 0.4 \mathrm{Ni} 5$ as the Working Metal Hydrides," International Journal of Hydrogen Energy, 35(11) pp. 5693-5702.

[9] Kelly, N. A., and Girdwood, R., 2012, "Evaluation of a Thermally-Driven Metal-Hydride-Based Hydrogen Compressor," International Journal of Hydrogen Energy, 37(14) pp. 10898-10916.

[10] Kim, J., Park, I., Kim, K. J., 2008, "A Hydrogen-Compression System using Porous Metal Hydride Pellets Of," International Journal of Hydrogen Energy, 33(2) pp. 870-877.

[11] Laurencelle, F., Dehouche, Z., Morin, F., 2009, "Experimental Study on a Metal Hydride Based Hydrogen Compressor," Journal of Alloys and Compounds, 475(1-2) pp. 810-816.

[12] Li, H., Wang, X., Dong, Z., 2010, "A Study on 70 MPa Metal Hydride Hydrogen Compressor," Journal of Alloys and Compounds, 502(2) pp. 503-507.

[13] Luo, G., Chen, J. P., Li, S. L., 2010, "Properties of La0.2Y0.8Ni5-xMnx Alloys for High-Pressure Hydrogen Compressor," International Journal of Hydrogen Energy, 35(15) pp. 8262-8267.

[14] Muthukumar, P., Prakash Maiya, M., and Srinivasa Murthy, S., 2005, "Experiments on a Metal Hydride Based Hydrogen Compressor," International Journal of Hydrogen Energy, 30(8) pp. 879-892.

[15] Muthukumar, P., Prakash Maiya, M., and Srinivasa Murthy, S., 2008, "Performance Tests on a Thermally Operated Hydrogen Compressor," International Journal of Hydrogen Energy, 33(1) pp. 463-469.

[16] Talagañis, B. A., Esquivel, M. R., and Meyer, G., 2009, "A Two-Stage Hydrogen Compressor Based on (La,Ce,Nd,Pr)Ni5 Intermetallics obtained by Low Energy Mechanical Alloying - Low Temperature Annealing Treatment," International Journal of Hydrogen Energy, 34(4) pp. 2062-2068.

[17] Wang, X. H., Bei, Y. Y., Song, X. C., 2007, "Investigation on High-Pressure Metal Hydride Hydrogen Compressors," International Journal of Hydrogen Energy, 32(16) pp. 4011-4015.

[18] Yu, W., Dianbo, X., Jianmei, F., 2010, "Research on Sealing Performance and Self-Acting Valve Reliability in High-Pressure Oil-Free Hydrogen Compressors for Hydrogen Refueling Stations," International Journal of Hydrogen Energy, 35(15) pp. 8063-8070.

[19] Lototskyy, M., Klochko, Y., Linkov, V., 2012, "Thermally Driven Metal Hydride Hydrogen Compressor for Medium-Scale Applications," Energy Procedia, 29(0) pp. 347-356.

[20] Bhuiya, M.M.H., Lee, C.Y., Hwang, T., Munira, S., Hopkins, R., Yoon, H., Park, S.H., Kim, K.J., 2014, "Experimentally tuned dual stage hydrogen compressor for improved compression ratio," International Journal of Hydrogen Energy, 39(24) pp. 12924-12933.

[21] Bhuiya, M.M.H., Lee, C.Y., Hopkins, R., Yoon, H., Kim, S., Park, S.H., Kim, K.J., "A High-Performance DualStage Hydrogen Compressor System Using $\mathrm{Ca}_{0.2} \mathrm{Mm}_{0.8} \mathrm{Ni}_{5}$," ASME 2011 Conference on Smart Materials, Adaptive Structures and Intelligent Systems, 2011/1/1

[22] Gopal, M. R., and Murthy, S. S., 1995, "Prediction of Metal-Hydride Refrigerator Performance Based on Reactor Heat and Mass Transfer," International Journal of Hydrogen Energy, 20(7) pp. 607-614. 
[23] Klein, H. and Groll, M., 2002, "Development of a Two-Stage Metal Hydride System as Topping Cycle in Cascading Sorption Systems for Cold Generation," Applied Thermal Engineering, 22(6) pp. 631-639.

[24] Lloyd, G., Razani, A., and Feldman Jr, K. T., 1998, "Transitional Reactor Dynamics Affecting Optimization of a Heat-Driven Metal Hydride Refrigerator," International Journal of Heat and Mass Transfer, 41(3) pp. 513527.

[25] Muthukumar, P., and Groll, M., 2010, "Erratum to "Metal Hydride Based Heating and Cooling Systems: A Review" [International Journal of Hydrogen Energy (2010) 35: 3817-3831]," International Journal of Hydrogen Energy, 35(16) pp. 8816-8829.

[26] Muthukumar, P., and Groll, M., 2010, "Metal Hydride Based Heating and Cooling Systems: A Review," International Journal of Hydrogen Energy, 35(8) pp. 3817-3831.

[27] Payá, J., Linder, M., Mertz, R., 2011, "Analysis and Optimization of a Metal Hydride Cooling System," International Journal of Hydrogen Energy, 36(1) pp. 920-930.

[28] Gopal, M. and Murthy, S., 1995, "Performance of a Metal Hydride Cooling System," International Journal of Refrigeration, 18(6) pp. 413-420.

[29] Ahmed, S. and Murthy, S., 2004, "Analysis of a Novel Metal Hydride Cycle for Simultaneous Heating and Cooling," Renewable Energy, 29(4) pp. 615-631.

[30] Suda, S., 1993, "What is Required for the Commercialization of Metal Hydride Refrigerators and Heat Pumps: Surface Engineering can Solve the Application Problems," Heat Recovery Systems and CHP, 13(4) pp. 309-314.

[31] Chernikov, A. S., Izhvanov, L. A., Solovey, A. I., 2002, "An Installation for Water Cooling Based on a Metal Hydride Heat Pump," Journal of Alloys and Compounds, 330-332(0) pp. 907-910.

[32] Choi, H., and Mills, A. F., 1990, "Heat and Mass Transfer in Metal Hydride Beds for Heat Pump Applications," International Journal of Heat and Mass Transfer, 33(6) pp. 1281-1288.

[33] Jang, K. -., Fateev, G. A., Park, J. -., 2001, "Simulation of the Metal Hydride Heat Pump System with the Single and Double Reactors," International Journal of Hydrogen Energy, 26(3) pp. 237-241.

[34] Kim, K. J., Feldman Jr, K. T., Lloyd, G., 1997, "Compressor-Driven Metal-Hydride Heat Pumps," Applied Thermal Engineering, 17(6) pp. 551-560.

[35] Libowitz, G. G., Feldman Jr., K. T., and Stein, C., 1997, "Thermodynamic Properties of Metal Hydrides for a Novel Heat Pump Configuration," Journal of Alloys and Compounds, 253-254(0) pp. 673-676.

[36] Linder, M., Mertz, R., and Laurien, E., 2010, "Experimental Results of a Compact Thermally Driven Cooling System Based on Metal Hydrides," International Journal of Hydrogen Energy, 35(14) pp. 7623-7632.

[37] Ni, J., and Liu, H., 2007, "Experimental Research on Refrigeration Characteristics of a Metal Hydride Heat Pump in Auto Air-Conditioning," International Journal of Hydrogen Energy, 32(13) pp. 2567-2572.

[38] Park, J., Jang, K., Lee, P. S., 2001, "The Operating Characteristics of the Compressor-Driven Metal Hydride Heat Pump System," International Journal of Hydrogen Energy, 26(7) pp. 701-706.

[39] Park, J., Han, S., Jang, H., 2002, "The Development of Compressor-Driven Metal Hydride Heat Pump (CDMHHP) System as an Air Conditioner," International Journal of Hydrogen Energy, 27(9) pp. 941-944.

[40] Suda S, Komazaki Y, Narasaki H, Uchida M, 1999, "Development of a double-stage heat pump: experimental and analytical surveys," Journal of Less-Common Metals, 172-174 pp. 1092-110.

[41] Dehouche Z, Jong WD, Willers E, Isselhorst A, Groll M, 1998, "Modelling and simulation of heating/airconditioning systems using the multi-hydride thermal wave concept," Applied Thermal Engineering; 18:45780

[42] Satheesh, A., and Muthukumar, P., 2010, "Performance Investigation of Double-Stage Metal Hydride Based Heat Pump," Applied Thermal Engineering, 30(17-18) pp. 2698-2707.

[43] Altinisik K, Veziroglu TN, 1991, "Metal Hydride Heat Pumps," International Journal of Energy Research, 15 pp. 549-560.

[44] Gopal, M.R., Murthy, S., 1999, "Experiments on a metal hydride cooling system working with $\mathrm{ZrMnFe} / \mathrm{MmNi}_{4.5} \mathrm{Al}_{0.5}$ pair", International Journal of Refrigeration, 22(2) pp. 137-149.

[45] Willers E, Groll M, 1999," Evaluation of metal hydride machines for heat pumping and cooling applications," International Journal of Refrigeration, 22(1) pp. 47-58.

[46] Satheesh, A., and Muthukumar, P., 2010, "Simulation of Double-Stage Double-Effect Metal Hydride Heat Pump," International Journal of Hydrogen Energy, 35(3) pp. 1474-1484. 
[47] Yang, F. S., Wang, G. X., Zhang, Z. X., 2010, "Investigation on the Influences of Heat Transfer Enhancement Measures in a Thermally Driven Metal Hydride Heat Pump," International Journal of Hydrogen Energy, 35(18) pp. 9725-9735.

[48] Arteconi, A., Hewitt, N. J., and Polonara, F., 2012, "State of the Art of Thermal Storage for Demand-Side Management," Applied Energy, 93(0) pp. 371-389.

[49] Bogdanović, B., Ritter, A., Spliethoff, B., 1995, "A Process Steam Generator Based on the High Temperature Magnesium Hydride/Magnesium Heat Storage System," International Journal of Hydrogen Energy, 20(10) pp. 811-822.

[50] Cabeza, L.F., 2012, "Comprehensive Renewable Energy,"Elsevier, Oxford, pp. 211-253.

[51] Reiser, A., Bogdanović, B., and Schlichte, K., 2000, "The Application of Mg-Based Metal-Hydrides as Heat Energy Storage Systems," International Journal of Hydrogen Energy, 25(5) pp. 425-430.

[52] Sakai, T., Honda, N., and Yonezu, I., 1986, "Metalhydride Container and Metal Hydride Heat Storage System," Journal of Heat Recovery Systems, 6(1) pp. vii.

[53] Semadeni, M., 2004, "Encyclopedia of Energy,"Elsevier, New York, pp. 719-738.

[54] Wakao, S., Sekine, M., Endo, H., 1983, "A Heat Storage Reactor for Metal Hydrides," Journal of the Less Common Metals, 89(2) pp. 341-350.

[55] Yang, F. S., Zhang, Z. X., and Bao, Z. W., 2012, "An Extensive Parametric Analysis on the Performance of a Single-Stage Metal Hydride Heat Transformer," International Journal of Hydrogen Energy, 37(3) pp. 26232634.

[56] Felderhoff, M., and Bogdanović, 2009, "High Temperature Metal Hydrides as Heat Storage Materials for Solar and Related Applications," International Journal of Molecular Science, 10(1) pp. 325-344.

[57] Verhelst, S., and Wallner, T., 2009, "Hydrogen-Fueled Internal Combustion Engines," Progress in Energy and Combustion Science, 35(6) pp. 490-527.

[58] Nomura, K., Ishido, Y., and Ono, S., 1979, "A Novel Thermal Engine using Metal Hydride," Energy Conversion, 19(1) pp. 49-57.

[59] Bhandari P, Prina M, Bowman Jr., RC, Paine C, Pearson D, Nash A, 2004, "Sorption coolers using a continuous cycle to produce $20 \mathrm{~K}$ for the Planck flight mission," Cryogenics, 44 pp. 395-401.

[60] Bowman Jr., RC, 2003, "Development of Metal Hydride Beds for Sorption Cryocoolers in Space Applications," Journal of Alloys and Compounds, 356-357 pp. 789-793.

[61] Prina M, Kulleck JG, and Bowman Jr., RC, 2002, "Assessment of Zr-V-Fe getter alloy for Gas-Gap Heat Switches," Journal of Alloys and Compounds, 330-332, pp. 886-891.

[62] Kaun TD, Nelson PA, Redey L, Vissers DR, and Henriksen GL, 1993, "High temperature lithium/sulphide batteries," Electrochimica Acta, 38 pp. 1269-1287.

[63] Prina M, Bowman Jr., RC, Kulleck JG, 2004, "Degradation study of $\mathrm{ZrNiH}_{1.5}$ for use as actuators in gas gap heat switches," Journal of Alloys and Compounds, 373 pp. 104-114.

[64] Prina M, Bhandari P, Bowman Jr., RC, Paine CG, Wade LA, 2000, "Development of gas gap heat switch actuator for the Planck sorption cryocooler," Shu QS (Ed.), Advances in cryogenic engineering 45A, Kluwer Academic/Plenum, New York, pp. 553-560. http://hdl.handle.net/2014/17732

[65] Ovshinsky, S. R., Fetcenko, M. A., and Ross, J., 1993, "A Nickel Metal Hydride Battery for Electric Vehicles," Science, 260(5105) pp. 176-181.

[66] Li, L., Tang, X., Luo, Z., 2010, "A Novel Parameter for Evaluation on Power Performance of Ni-MH Rechargeable Batteries," International Journal of Hydrogen Energy, 35(7) pp. 2847-2851.

[67] Fan, C. Q., Rivera, H., Rao, U., 2012, "Applications of Metal Hydride-Based Bipolar Electrodes," Electrochimica Acta, 59(0) pp. 470-473.

[68] Nei, J., 2012, "Multi-Component AB2 Metal Hydride Alloys for Nickel Metal Hydride Battery Applications," ProQuest Dissertations and Theses, .

[69] Bäuerlein, P., Antonius, C., Löffler, J., 2008, "Progress in High-Power Nickel-metal Hydride Batteries," Journal of Power Sources, 176(2) pp. 547-554.

[70] Nan, J., Han, D., Yang, M., 2006, "Recovery of Metal Values from a Mixture of Spent Lithium-lon Batteries and Nickel-Metal Hydride Batteries," Hydrometallurgy, 84(1-2) pp. 75-80.

[71] Cuscueta, D. J., Ghilarducci, A. A., and Salva, H. R., 2010, "Design, Elaboration and Characterization of a NiMH Battery Prototype," International Journal of Hydrogen Energy, 35(20) pp. 11315-11323. 
[72] Su, G., He, Y., and Liu, K., 2012, "Effects of $\mathrm{Co} 3 \mathrm{O} 4$ as Additive on the Performance of Metal Hydride Electrode and Ni-MH Battery," International Journal of Hydrogen Energy, 37(16) pp. 11994-12002.

[73] Kopera, J.J.C., 2004, "Inside the Nickel Metal Hydride Battery," COBASYS, .

[74] ART., 04/18/2013, "Fuel Cell: Proton Exchange Membrane Fuel Cell <http://Kids.Britannica.Com/Comptons/Art-106689>," Britannica Online for Kids, .

[75] Kim, T., 2012, "Fully-Integrated Micro PEM Fuel Cell System with NaBH4 Hydrogen Generator," International Journal of Hydrogen Energy, 37(3) pp. 2440-2446.

[76] Zhu, L., Kim, D., Kim, H., 2008, "Hydrogen Generation from Hydrides in Millimeter Scale Reactors for Micro Proton Exchange Membrane Fuel Cell Applications," Journal of Power Sources, 185(2) pp. 1334-1339.

[77] Anonymous 2010, "Linde MH Delivers Fuel Cell Forklifts to Linde Gases," Fuel Cells Bulletin, 2010(3) pp. 4.

[78] Mori, D., and Hirose, K., 2009, "Recent Challenges of Hydrogen Storage Technologies for Fuel Cell Vehicles," International Journal of Hydrogen Energy, 34(10) pp. 4569-4574.

[79] Nice, Karim, and Jonathan Strickland, " "How Fuel Cells Work" 18 September 2000. HowStuffWorks.Com. $<$ http://Auto.Howstuffworks.Com/Fuel-Efficiency/Alternative-Fuels/Fuel-Cell.Htm> 18 April 2013." .

[80] Anonymous 2002, "Metal Hydride Artificial Muscles," Smart Materials Bulletin, 2002(7) pp. 14.

[81] Alexandra Vanderhoff and Kwang, J. K., 2009, "Experimental Study of a Metal Hydride Driven Braided Artificial Pneumatic Muscle," Smart Materials and Structures, 18(12) pp. 125014.

[82] Ino, S., Sato, M., Hosono, M., 2009, "Development of a Soft Metal Hydride Actuator using a Laminate Bellows for Rehabilitation Systems," Sensors and Actuators B: Chemical, 136(1) pp. 86-91.

[83] Kurosaki, K., Maruyama, T., Takahashi, K., 2004, "Design and Development of MH Actuator System," Sensors and Actuators A: Physical, 113(1) pp. 118-123.

[84] Lloyd, G. M., and Kim, K. J., 2007, "Smart Hydrogen/Metal Hydride Actuator," International Journal of Hydrogen Energy, 32(2) pp. 247-255.

[85] Marie-Charlotte Crevier and Martin Richard and D Matheson Rittenhouse and Pierre-Olivier Roy, and St, 2007, "Artificial Exomuscle Investigations for Applications - metal Hydride," Biomedical Materials, 2(1) pp. S1.

[86] Sandrock, G., and Bowman Jr., R. C., 2003, "Gas-Based Hydride Applications: Recent Progress and Future Needs," Journal of Alloys and Compounds, 356-357(0) pp. 794-799.

[87] Sato, M., Hosono, M., Yamashita, K., 2011, "Solar Or Surplus Heat-Driven Actuators using Metal Hydride Alloys," Sensors and Actuators B: Chemical, 156(1) pp. 108-113.

[88] Choe, K., Kim, K. J., Kim, D., 2006, "Performance Characteristics of Electro-Chemically Driven Polyacrylonitrile Fiber Bundle Actuators," Journal of Intelligent Material Systems and Structures, 17(7) pp. 563-576.

[89] DiMeo Jr., F., Chen, I., Chen, P., 2006, "MEMS-Based Hydrogen Gas Sensors," Sensors and Actuators B: Chemical, 117(1) pp. 10-16.

[90] Slaman, M., Dam, B., Pasturel, M., 2007, "Fiber Optic Hydrogen Detectors Containing mg-Based Metal Hydrides," Sensors and Actuators B: Chemical, 123(1) pp. 538-545.

[91] Karazhanov, S.Zh. and Ulyashiny, A.G., 2010, "Similarity of Optical Properties of Hydrides and Semiconductors for Antireflection Coatings," Philosophical Magazine, 90(21) pp. 2925.

[92] Kirby, D. J., Chang, D. T., Stratton, F. P., 2009, "A Differential Capacitive Thin Film Hydrogen Sensor," Sensors and Actuators B: Chemical, 141(2) pp. 424-430.

[93] Huiberts, J. N., Griessen, R., Rector, J. H., Wijngaarden, R. J., Dekker, J. P., de Groot, D. G., Koeman, N. J, 1996/03/21, "Yttrium and Lanthanum Hydride Films with Switchable Optical Propertie," Nature, 380(6571) pp. 231-234.

[94] Mongstad, T., Platzer-Björkman, C., Karazhanov, S. Z., 2011, "Transparent Yttrium Hydride Thin Films Prepared by Reactive Sputtering," Journal of Alloys and Compounds, 509, Supplement 2(0) pp. S812-S816.

[95] Anders, A., Slack, J. L., and Richardson, T. J., 2008, "Electrochromically Switched, Gas-Reservoir Metal Hydride Devices with Application to Energy-Efficient Windows," Thin Solid Films, 517(3) pp. 1021-1026.

[96] Block, F. R., Dey, A., Kappes, H., 1987, "Hydrogen Purification with Metal Hydrides in a New Kind of Reactor," Journal of the Less Common Metals, 131(1-2) pp. 329-335.

[97] Miura, S., Fujisawa, A., Tomekawa, S., "A Hydrogen Purification and Storage System using CO Adsorbent and Metal Hydride," Journal of Alloys and Compounds, 580(S1) pp. S414-S417. 
[98] Fujisawa, A., Miura, S., Mitsutake, Y., 2013, "Simulation Study of Hydrogen Purification using Metal Hydride," Journal of Alloys and Compounds, 580(S1) S423-S426.

[99] Saitou, T., and Sugiyama, K., 1995, "Hydrogen Purification with Metal Hydride Sintered Pellets using Pressure Swing Adsorption Method," Journal of Alloys and Compounds, 231(1-2) pp. 865-870.

[100] Miura, S., Fujisawa, A., and Ishida, M., 2012, "A Hydrogen Purification and Storage System using Metal Hydride," International Journal of Hydrogen Energy, 37(3) pp. 2794-2799.

[101] Brodowsky, H., 1968, "Book Review: The Palladium-Hydrogen System. by F. A. Lewis," Angewandte Chemie International Edition in English, 7(6) pp. 487-487.

[102] Heung, L. K., Tran, R. S., and Stoner, K. J., 1991, "Metal Hydride Compacts for Hydrogenisotope Separation," Journal of the Less Common Metals, 172-174, Part 3(0) pp. 1313-1319.

[103] Choppin, G.R., Liljenzin, J., and Rydberg, J., 2002, "Radiochemistry and Nuclear Chemistry (Third Edition),"Butterworth-Heinemann, Woburn, pp. 11-40.

[104] Krishtalik, L. I., and Tsionsky, V. M., 1971, "Mechanism of the Elementary Act of Proton Transfer. Preexponential Factor and Hydrogen Isotope Separation Factor," Journal of Electroanalytical Chemistry and Interfacial Electrochemistry, 31(2) pp. 363-374.

[105] Ito, Y., Takahashi, R., Mizusaki, S., 2006, "Magnetic Field Effects on the Hydrogen Isotope Separation with Metal Hydrides," Science and Technology of Advanced Materials, 7(4) pp. 369-372.

[106] Mimoun, H., 1999, "Selective reduction of carbonyl compounds by polymethylhydrosiloxane in the presence of metal hydride catalysts," Journal of Organic Chemistry, 64 pp. 2582-2589.

[107] Pez, G. P., Grey, R. A., and Corsi, J., 1981, "Anionic Metal Hydride catalysts. 1. Synthesis of Potassium Hydrido(phosphine)ruthenate Complexes," Journal of American Chemical Society, 103 pp. 7528-7535.

[108] Grey R. A., Pez G. P., and Wallo A., 1981, "Anionic Metal Hydride catalysts. 2. Application to the hydrogenation of Ketones, Aldehydes, Carboxylic Acid Esters, and Nitriles," Journal of American Chemical Society, 103, 7536-7542.

[109] Imamura, H., Tanaka, T., Sakata, Y., and Tsuchiya, S., 1999, "Transfer of olefin from alcohol using a hydrogen-absorbing alloy (CaNi5) catalyst," Journal of Alloys and Compounds, 293-295 pp. 919-922.

[110] Imamura, H., Noda, Y., Sakata, Y., and Tsuchiya, S., 2001, "Catalytic transfer hydrogenation of butene on hydrogen-absorbing alloys (LaNi5, CaNi5 and LaNi4Al)," Journal of Alloys and Compounds, Vol. 323-324, pp. 601-604

[111] Iwata, K., Sun, Y. M., and Suda S, 1999, "A recovery of carbon oxides by methanation reaction through a pressure-temperature swing process by applying active protium in the fluorinated metal hydride," Internation Journal of Hydrogen Energy, 24 pp. 251-256.

[112] Karazhanov, S. Z., Ulyashin A.G., Ravindran P. and Vajeeston P., 2008, "Semiconducting Hydrides," EPL (Europhysics Letters), 82(1) pp. 17006.

[113] Karazhanov, S. Z., Ulyashin, A. G., Vajeeston, P., 2008, "Hydrides as Materials for Semiconductor Electronics," Philosophical Magazine, 88(16) pp. 2461-2476.

[114] Leephakpreeda, T., 2012, "Mathematical Modeling of Pneumatic Artificial Muscle Actuation Via Hydrogen Driving Metal Hydride-LaNi5," Journal of Bionic Engineering, 9(1) pp. 110-118.

[115] Barreiro, M. M., Grana, D. R., Kokubu, G. A., Luppo M. I., Mintzer, S. and Vigna, G., 2010, "Titanium Compacts Produced by the Pulvimetallurgical Hydride-dehydride Method for Biomedical Applications," Biomedical Materials, 5(2) pp. 025010.

[116] Van Houten, R., 1974, "Selected Engineering and Fabrication Aspects of Nuclear Metal Hydrides (Li, Ti, Zr, and Y)," Nuclear Engineering and Design, 31(3) pp. 434-448.

[117] Konashi, K., and Yamawaki, M., 2012, "Environmentally Friendly Application of Hydrides to Nuclear Reactor Cores," Advances in Applied Ceramics: Structural, Functional \& Bioceramics, 111(1) pp. 106-111.

[118] S. S. Murthy, 2012, " Heat and Mass Transfer in Solid State Hydrogen Storage: A Review; Trans. ASME Journal of Heat Transfer, 134 pp.1-11.

[119] U.A.R. Prasad, M.P. Maiya and S. S. Murthy, 2004, "Metal Hydride Water Pumping System for Low Headhigh Discharge Applications," Int. J of Hydrogen Energy, 29(5) pp. 501-508. 


\section{Acknowledgements}

KJK thanks partial financial support from Southwest Gas Corporation. Also, KJK appreciate partial financial support from the US Department of Energy/National Renewable Energy Laboratory (Subcontract No: NAX-9-66014-06). 